\title{
Development and evaluation of a global dynamical wetlands extent scheme
}

\author{
T. Stacke and S. Hagemann \\ Max-Planck-Institut für Meteorologie, Bundesstraße 53, 20146 Hamburg, Germany \\ Correspondence to: T. Stacke (tobias.stacke@zmaw.de) \\ Received: 13 December 2011 - Published in Hydrol. Earth Syst. Sci. Discuss.: 10 January 2012 \\ Revised: 30 July 2012 - Accepted: 30 July 2012 - Published: 23 August 2012
}

\begin{abstract}
In this study we present the development of the dynamical wetland extent scheme (DWES) and evaluate its skill to represent the global wetland distribution. The DWES is a simple, global scale hydrological scheme that solves the water balance of wetlands and estimates their extent dynamically. The extent depends on the balance of water flows in the wetlands and the slope distribution within the grid cells. In contrast to most models, the DWES is not directly calibrated against wetland extent observations. Instead, wetland affected river discharge data are used to optimise global parameters of the model. The DWES is not a complete hydrological model by itself but implemented into the Max Planck Institute - Hydrology Model (MPI-HM). However, it can be transferred into other models as well.

For present climate, the model evaluation reveals a good agreement for the spatial distribution of simulated wetlands compared to different observations on the global scale. The best results are achieved for the Northern Hemisphere where not only the wetland distribution pattern but also their extent is simulated reasonably well by the DWES. However, the wetland fraction in the tropical parts of South America and Central Africa is strongly overestimated. The simulated extent dynamics correlate well with monthly inundation variations obtained from satellites for most locations. Also, the simulated river discharge is affected by wetlands resulting in a delay and mitigation of peak flows. Compared to simulations without wetlands, we find locally increased evaporation and decreased river flow into the oceans due to the implemented wetland processes.

In summary, the evaluation demonstrates the DWES' ability to simulate the distribution of wetlands and their seasonal variations for most regions. Thus, the DWES can provide hydrological boundary conditions for wetland related studies.
\end{abstract}

In future applications, the DWES may be implemented into an Earth system model to study feedbacks between wetlands and climate.

\section{Introduction}

In recent studies wetlands are suspected to play an important role during periods of climate change (e.g. Ringeval et al., 2011; Gedney et al., 2004; Levin et al., 2000). However, the representation of the wetland's spatial extent and its temporal variations is still a weak point in today's Earth System Models (ESMs) and needs to be improved by a better simulation of their hydrological cycle (O'Connor et al., 2010; Ringeval et al., 2010). Besides the wetland extent, the water level is an important factor for the wetland's biogeochemistry which results in carbon sequestration or decomposition (e.g. O'Connor et al., 2010, and references therein). In the saturated soil zone, below the water table, anoxic conditions prevail which are favourable for methane producing microbes. Depending on factors like temperature, available substrate and $\mathrm{pH}$, organic material is decomposed and methane is produced. While methane diffuses upwards, it can be oxidised to $\mathrm{CO}_{2}$ within the unsaturated oxic soil zone above the water table. Thus, the water table determines the separation of soil into a methane producing and a methane oxidising zone. While most studies identify wetlands as net carbon sinks for today's climate conditions (Bohn et al., 2007; Gorham, 1991; Friborg et al., 2003), a number of studies concluded that some wetlands might turn into carbon sources in a warmer climate (St-Hilaire et al., 2010; Gorham, 1991) due to higher productivity of methane releasing microbes. 
However, even without consideration of the carbon cycle, the wetland hydrology in itself is an important key factor in the climate system. Wetlands are often related to regions with open surface water and saturated soil. Such regions have to be considered in ESMs because of their potential feedbacks to the atmosphere (Coe and Bonan, 1997). The effect of open water surfaces on the energy and water balance was investigated by several modelling studies, e.g. Bonan (1995) and Mishra et al. (2010), who reported a significant impact of wetlands on the local climate. Generally, they found a cooling of the surface temperature in wetland dominated regions due to increased evapotranspiration (ET), as well as an increase in the latent heat flux and a decrease in the sensible heat flux. Eventually, this could result in increased precipitation rates as shown by Coe and Bonan (1997) and Krinner et al. (2012). Furthermore, wetlands interact in several ways with the hydrological cycle of their surrounding area. They are commonly expected to regulate river flow, mitigate flood events and recharge groundwater. These observations are consistent with a modelling study by Mishra et al. (2010) who found decreased surface runoff in wetland dominated regions. However, a number of studies exists that describe the opposite behaviour (Bullock and Acreman, 2003). All of these processes are of great interest for impact studies that investigate how climate change might effect the water storage capacities in a region or the characteristics of river flooding.

In our study we focus on modelling the hydrological cycle in wetlands and their extent dynamics, which we see as a prerequisite for the computation of the wetland carbon cycle. This issue already motivated a large number of modelling studies. Generally, most models follow one of two main approaches for the hydrological representation of wetlands.

One approach is concerned with the redistribution of soil moisture in the model grid cell. A widely used example is TOPMODEL (Beven and Kirkby, 1979). In this approach a topographical index is computed that depends on the drainage of a given area routed through a point and its slope. This index is then applied to determine the position of the local water table at that point relative to the mean water table of the whole grid cell. The grid cell fraction where the sub-grid soil moisture exceeds the soil moisture storage capacity of the grid cell is then regarded as a wetland. The TOPMODEL approach is used and improved in several studies (e.g. Barling et al., 1994; Gedney et al., 2004; Bohn et al., 2007; Kleinen et al., 2012) and able to compute changes in wetland extent as well. While this approach is an elegant solution, we see in it one major problem. As the wetland fraction depends on the redistribution of the mean grid cell soil moisture, it follows that there is an upper boundary for the maximum water depth and wetland fraction. For the extreme case of a grid cell with zero slope no wetland can emerge because the mean soil moisture can obviously not exceed the maximum soil moisture capacity. However, observations indicate that flat regions appear to be more suitable for wetland formation.
The second approach is the explicit modelling of surface water. In this case depressions in the topography are identified and filled with water that results from a positive water balance. On the one hand, this can be done on a continental scale (e.g. Coe, 1997, 1998, 2000) but then the quality of the wetland representation is strongly limited by resolution of the model. Alternatively, regional models allow for a higher resolution but then depend strongly on detailed soil property information (e.g. Bowling and Lettenmaier, 2010; Yu et al., 2006) or are calibrated for specific catchments (e.g. Bohn et al., 2007). Decharme et al. $(2008,2011)$ developed a global inundation model, but its focus is concentrated on the representation of floodplains.

In contrast to these sophisticated approaches, we wanted to develop a more simple hydrological scheme that represents the global distribution and extent variability of very different types of wetlands. The scheme is designed for the application in complex ESMs on global scale with medium to coarse resolutions ( $50 \mathrm{~km}$ or coarser), because we think that the representation of surface water dynamics is - albeit important - not strongly developed in such models. While an explicit representation of wetland dynamics is necessary for the calculation of $\mathrm{CH}_{4}$ emissions, we also expect an improved simulation of the hydrological cycle due to our scheme. From this objective several limitations arise. Of course, we strive for a realistic representation of wetland extent but nevertheless our approach needs to be simple. It should be easily implementable into different ESMs and should only require boundary data that is readily available on global scale. By these means, we want to minimise the necessity to recalibrate our model parameters for different applications or setups of the ESM in order to allow for future projections and hindcast experiments as well as for present day simulations. Therefore, we restrict our scheme to the use of the general water balance terms, which are considered in all ESMs, and topographical data, which is globally available. One example for an already existing wetland model of similar complexity is the study of Krinner (2003). The author relates wetland extent dynamically to the total quantity of water in wetlands and the mean topographic index of the grid cell. However, they prescribe their wetland dynamics with an upper boundary based on observation and do not consider any horizontal surface water routing between grid cells. In our study we want to overcome these limitations.

The first part of this paper is concerned with the development of the dynamical wetland extent scheme (DWES). In this section we give detailed information about the basic approach underlying the DWES and its parameter optimisation. In the second part, the model's ability to represent wetland extent is evaluated using different global wetland observations. Here, we focus on the global distribution of large scale wetlands and their seasonal variation. In the third part we discuss the impact of wetlands on different components of the terrestrial water cycle and give information on the limitations of our approach. 


\section{Model development}

The DWES is not a stand alone model by itself but needs to be implemented into a large scale model. Instead of starting the model development directly within the framework of an ESM, the Max Planck Institute - Hydrology Model (MPI$\mathrm{HM}$ ) was chosen as a test environment for the development of the DWES. The MPI-HM computes the global water cycle only and thus it is possible to investigate the direct effects of the DWES before indirect effects due to interactions with other ESM components occur.

\subsection{The MPI-HM}

The MPI-HM is a global hydrological model which solves the land surface water balance at a horizontal resolution of $0.5^{\circ}$ with a time step of 1 day. It is restricted to the computation of water fluxes and does not consider any energy balance calculations. The MPI-HM consists of two formerly separated sub-components, the Simplified Land surface Scheme (SL-Scheme) (Hagemann and Dümenil Gates, 2003) and the Hydrological Discharge Model (HD-Model) (Hagemann and Dümenil, 1998, 1999; Hagemann and Dümenil Gates, 2001). The SL-Scheme includes a simple snow scheme based on the degree day approach (e.g. Rango and Martinec, 1995) and uses a soil bucket scheme for the computation of the vertical water balance. Most of its water flux calculations are functions of the relative saturation of the soil storage. The main outputs of the SL-Scheme are daily fields of runoff and drainage. These are given to the HD-Model, which is a state of the art river routing model. It computes the retention time of water in overflow, baseflow and riverflow reservoirs using a linear reservoir cascade (Singh, 1988). Horizontal outflow from a storage is given to the river flow reservoir of the downstream grid cell. The river flow net is computed based on elevation data and manually adjusted for major catchments. As wetlands are subject to vertical as well as horizontal water fluxes simultaneously, both water balances have to be solved during every model time step. Thus, the SL-Scheme and HDModel were coupled to form the MPI-HM.

The MPI-HM requires daily temperature and precipitation data as climate forcing. Both data fields were taken from the WATCH Forcing Data (WFD) (Weedon et al., 2011) which is a quasi-observational dataset. Optionally, it is possible to use prescribed forcing for potential evapotranspiration (PET) instead of relying on the native PET calculation in the MPIHM, which is based on the Thornthwaite formula (Thornthwaite and Mather, 1955). In order to derive PET forcing that is consistent with the WFD, we adopted the Weedon et al. (2011) method for PET calculation and applied the PenmanMonteith reference ET as proxy for PET. Following their study and the FAO recommendations (Allen et al., 1998) we used globally constant parameters of short grass for the crop height and aerodynamic resistance.
In this study all simulations were conducted for the period 1958-1999. The first five years are used to spin-up different MPI-HM storages and are excluded from the optimisation and the analysis of the results.

\subsection{Wetland dynamics}

In our approach, wetlands are defined as the occurrence of surface water that covers a certain area fraction in a model grid cell. Following our simplicity criteria, we decided not to differentiate the treatment of different wetland types and lakes but to use a general approach instead. For this approach we make two preconditions: first, that wetland formation requires excess water on the land surface and second, that wetlands form preferentially on the flat parts of a grid cell.

As starting point for the parametrization of wetland dynamics we assume that the water balance of a wetland depends directly on its surface extent. For example, a wetland with a small surface extent would loose less water volume due to open water evaporation than a larger wetland. However, a small wetland would also gain less water volume from horizontal inflow than a larger wetland, because a small wetland is easily bypassed by rivers in this region. Analysing the water balance fluxes separately, we see that the volume of vertical water fluxes (e.g. precipitation, evaporation and drainage) depend linearly on the wetland extent. However, horizontal fluxes (e.g. river inflow from upstream grid cells or outflow from the wetland) have a more complex, non-linear relation with the wetland extent as explained in the detailed discussion of the wetland water balance in Sect. 2.3. Thus, the overall wetland inflow $I$ (Eq. 1) and outflow $O$ (Eq. 2) at a given time step $i$ are sums of water flows which depend on wetland extent in a linear as well as a non-linear manner. They are indicated with the subscripts $l$ for linear flows and n for non-linear flows, respectively.

$$
\begin{aligned}
I_{i} & =\sum I_{i, l}+\sum I_{i, n} \\
O_{i} & =\sum O_{i, l}+\sum O_{i, n}
\end{aligned}
$$

As the non-linear extent dependencies are different for inflows and outflows, they are balanced only for a certain extent as shown in Fig. 1. This extent would be the stable wetland extent under the given climatic forcing. If the actual wetland extent is smaller than the stable extent, wetland outflow is less than the inflow and the excess water (blue shaded area in Fig. 1) is used to increase the wetland extent towards its stable extent. If the wetland is larger than the stable extent, its outflow exceeds the inflow. Thus, the wetland looses water (red shaded area in Fig. 1) and shrinks towards the stable extent. As climate forcing is not constant but varies from one model time step to the other, the stable extent varies as well.

Additionally, the wetland dynamics are constrained by the topography of their surrounding. Assuming that wetlands preferably form on low slopes, we use the sub-grid distribution of slope in the model grid cells as a resistance factor against wetland extent changes. This results in different 


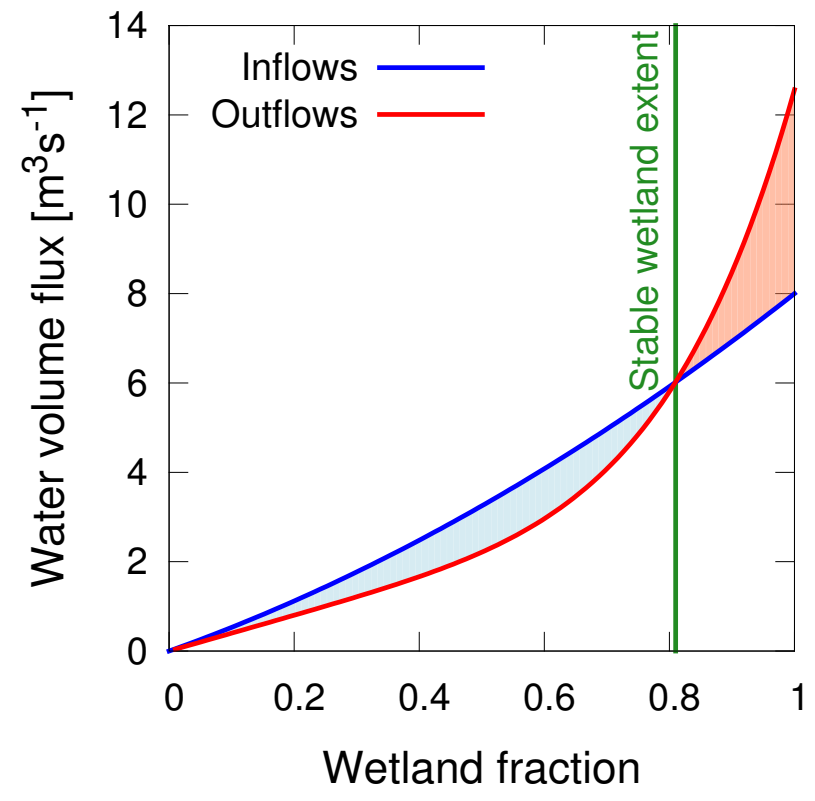

Fig. 1. Conceptual sketch of wetland water inflows (blue curve) and outflows (red curve) in dependence on the wetland's surface area. The stable wetland extent (green line) is found on the intersection of both curves and depend on climatic forcing during the respective model time step and the topography of the grid cell. The blue shaded area indicates excess water if the inflow exceeds the outflow and vice versa for the red shaded area.

wetland extent response times in respect to changes in the climatic conditions. Thus, wetland formation is promoted on low slopes and suppressed on steeper regions. The effect is further enhanced because steeper slopes also increase the amount of horizontal wetland outflow (see Sect. 2.3). In order to consider slope information in our approach, highly resolved topographical information is required. Such information is available in the GTOPO30 dataset (Gesch et al., 1999) which provides elevations for the global land surface at $30 \mathrm{arc} \mathrm{sec} \mathrm{horizontal} \mathrm{resolution.} \mathrm{Based} \mathrm{on} \mathrm{these} \mathrm{data,} \mathrm{slope}$ information were derived resulting in 3600 slope values for every $0.5^{\circ}$ sized grid cell of the MPI-HM. As this amount of information would increase the computational requirements of the MPI-HM significantly, we had to represent the slope information in a reduced way. First, the sub-grid slope values for every grid cell were sorted. Thus, the slope is directly related to the grid cell fraction as shown in Fig. 2. Furthermore, the fraction-slope relation was approximated using Eq. (3). This equation is a modified version of the formula that was successfully used by Hagemann and Dümenil Gates (2003) to account for sub-grid heterogeneity. The maximum subgrid slope $s(f)$ for the grid cell fraction $f$ can be described as

$$
\begin{aligned}
s(f) & =\operatorname{MAX}\left[\left(1-(1-f)^{\frac{1}{b}}\right) \cdot s_{\text {range }}+s_{\min }, 0\right], \text { with } \\
s_{\text {range }} & =s_{\max }-s_{\min }
\end{aligned}
$$

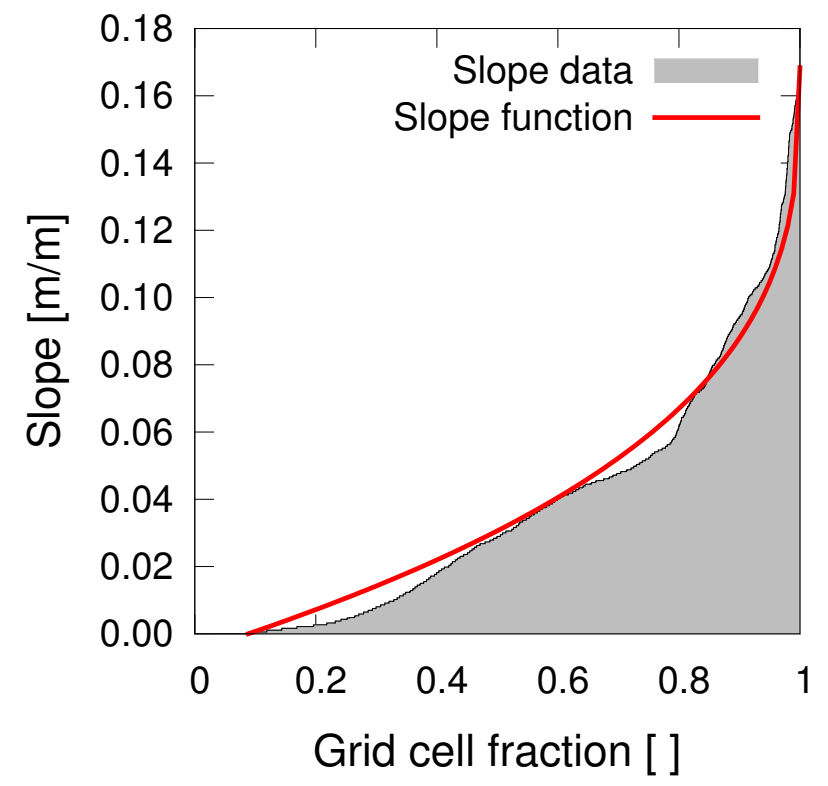

Fig. 2. Maximum sub-grid slopes that occurs for a given grid cell fraction. The grey area displays discrete slope data derived from the GTOPO30 dataset for an example MPI-HM grid cell. The red line displays an analytical approximation of these data based on Eq. (3).

where $b$ is a shape parameter accounting for the curvature of the curve and $s_{\text {range }}$ is the difference between the maximum slope $s_{\max }$ and minimum slope $s_{\min }$ of the grid cell. While $s_{\max }$ and $s_{\min }$ can be derived directly from the data, $b$ needs to be derived by least-squares fitting. For the majority of grid cells, this function can be fitted very well to the sub-grid slope distribution with an asymptotic standard error below $1 \%$.

In the DWES the stable wetland extent is not computed analytically. Instead, only the change in wetland extent is estimated using an iterative procedure based on the residuum $\Delta V$ of the water balance calculation $\left(\Delta V=\sum \Delta S\right.$ of Eq. 6). In Eq. (4) we relate the relative change of the wetland water volume $V$ to the relative change in wetland extent $f_{\mathrm{w}}$. Thus, we ensure that the amount of wetland extent change is adjusted to the mismatch between the actual wetland extent and the stable extent where the water balance residuum would converge against zero. The change in wetland extent $\Delta f_{\mathrm{w}}$ is then computed as

$$
\begin{aligned}
\Delta f_{\mathrm{w}} & =\frac{\Delta V}{V} \times \tau \times \frac{1}{f_{\mathrm{w}}}, \text { with } \\
\tau & =\frac{1}{1+s\left(f_{\mathrm{w}}\right) \times \kappa}
\end{aligned}
$$

where $\tau$ describes the resistance against a change in wetland extent due to the effect of the maximum slope $s\left(f_{\mathrm{w}}\right)$ covered by the wetland in the respective grid cell and the sensitivity $\kappa$ of the extent change to the topographic conditions. $\kappa$ needs to be optimised to account for the resolution of the MPI-HM. Its optimisation is described in Sect. 2.4. For non-wetland 
model grid cells, $f_{\mathrm{w}}$ is initialised with a minimum grid cell fraction that is the larger value of either $1 \times 10^{-10}$ or the grid cell fraction with zero slope.

An additionally constraint for $\Delta f_{\mathrm{w}}$ is given by the wetland water level $h$. The level $h$ is the height of the water column above the soil surface. Its average value is given as $h=V /\left(f_{\mathrm{w}} \times A_{\mathrm{gc}}\right)$ with $A_{\mathrm{gc}}$ as grid cell area. In case of wetland growth $f_{\mathrm{w}}$ is only allowed to increase by a fraction that does not decrease $h$ and vice versa for a shrinking wetland. This constrain promotes a steady change in wetland extent and prevents strong oscillations around the stable extent.

\subsection{Wetland water balance}

The DWES does not explicitly distinguish between different kinds of wetlands. However, it is useful for the comprehensibility of our approach to focus the explanation of water balance calculation on the two extremes in the range of wetland types. Being restricted to hydrological indices, wetland types differ only in the relation of their water fluxes. A domination of vertical water fluxes leads to the formation of saturated wetlands. These are usually located in regions where precipitation exceeds evaporation. In contrast, a domination of horizontal water fluxes results in floodplains. They form close to rivers due to inundation. Most wetland models focus on the simulation of either saturated wetlands (e.g. Krinner, 2003; Gedney et al., 2004; Kleinen et al., 2012) or floodplains (Decharme et al., 2008, 2011). Thus, a key feature of the DWES is that we couple sub-models for the calculation of both, vertical and horizontal, water fluxes to allow for the simultaneous computation of both processes as well as consider wetlands which are intermediate between the water flux regimes.

The general wetland water balance is given by Eq. (6) and displayed in Fig. 3. The change in the soil moisture and surface water storages $\sum \Delta S$ for a given time period $t$ is given by the balance of inflowing and outflowing wetland water fluxes as

$\sum \Delta S=(P-\mathrm{ET}-D+I-O) \times \Delta t$

where $P$ is precipitation, ET is evapotranspiration, $D$ is subsurface drainage, and $I$ and $O$ are the horizontal inflows and outflows of water, respectively. As all fluxes are computed as volumes, $\sum \Delta S$ equals the water balance residuum $\Delta V$ that is required in Eq. (4) for the computation of wetland dynamics.

Saturated wetlands are dominated by the first three terms of Eq. (6). Their computation is strongly based on the routines of the former SL-Scheme part of the MPI-HM. First, precipitation forcing is separated into rainfall and snowfall depending on surface air temperature. Only liquid precipitation is then allowed to enter the wetland fraction of the grid cell. Depending on its relative soil moisture content, ET and drainage are computed such that they converge against PET and the maximum drainage value when the soil moisture

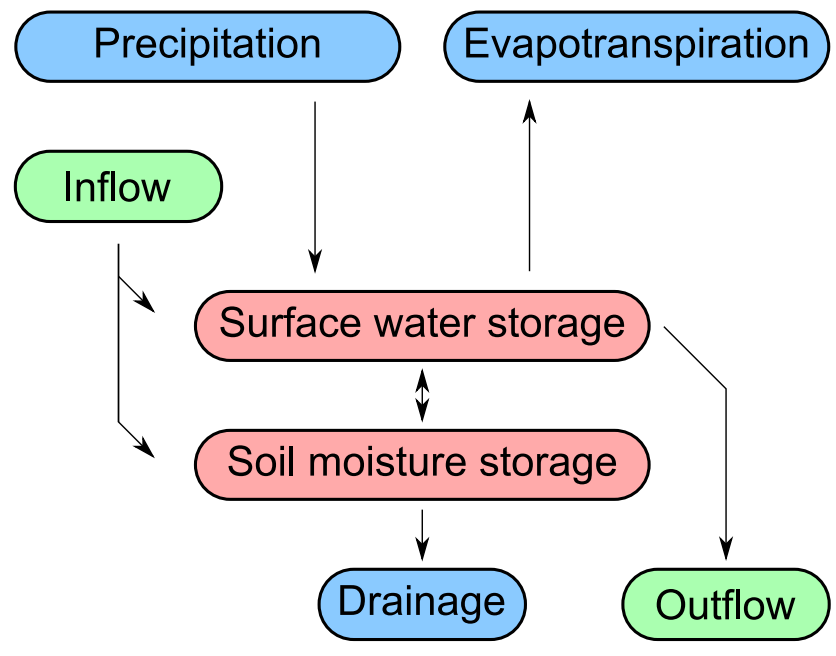

Fig. 3. Wetland water balance as simulated by the DWES. The green boxes indicate horizontal water flows, the blue ones indicate vertical water flows, and the red ones indicate water storages. Please note that horizontal inflow can fill the soil moisture storage as well as the surface water storage of the wetlands. However, horizontal outflow is only generated during periods when surface water exists in the respective wetland.

storage converges against the field capacity. Only then, surface water is allowed to build up in the grid cell. While PET is computed using the Penman-Monteith equation (Allen et al., 1998; Weedon et al., 2011), the maximum drainage value had to be estimated. Our estimate is based on the average residuum $R$ of the precipitation - PET difference for all grid cells which are known to contain wetlands in today's observations. Assuming that these wetlands are hydrologically stable under the current climatic condition, the average drainage must not exceed $R$ because otherwise the wetland would dessicate. Horizontal flows are neglected in this case. Thus, the maximum drainage value is set to $R$. It corresponds to about $10 \%$ of the maximum drainage value for the nonwetland grid cells. As the MPI-HM lacks an energy balance, it is difficult to account for the freezing of wetlands. In the MPI-HM, only precipitation is affected by low temperatures. Below $3.3{ }^{\circ} \mathrm{C}$, some part of the precipitation is treated as snow. The fraction is gradually increasing and reaches $100 \%$ below $-1.1^{\circ} \mathrm{C}$. While rainfall is added to the wetland water balance at once, the input of snowfall is delayed. Snow is stored on the wetland surface as if the wetland would be frozen and it is only allowed to enter the wetland water balance as melt water. Snow melt is calculated based on the degree day approach (e.g. Rango and Martinec, 1995) similar to the original SL-Scheme routines. All other processes are treated similar during frost and no frost periods.

The SL-Scheme treats precipitation, ET and drainage as one dimensional, vertical fluxes. They are converted into water volume via multiplication with the wetland extent. Thus, they depend linearly on the extent of the wetlands. 
In contrast to saturated wetlands, floodplains are dominated by horizontal water flows. These flows are computed by the HD-Model part of the MPI-HM. Every grid cell receives a certain inflow $I_{\mathrm{gc}}$ that is generated by its upstream grid cells. $I_{\mathrm{gc}}$ has to be separated into the inflow $I$ that reaches the wetland and the inflow $I_{\mathrm{r}}$ that remains in the river. To our knowledge, no observations are available about the distribution of river flow into all surface water bodies of a grid cell sized area at a resolution of $0.5^{\circ} \times 0.5^{\circ}$. However, even if such data were available for some regions, we doubt that it could be used to derive a separation parametrization for the whole land surface. Thus, we tried a simple concept to find a useful and globally applicable parametrization for this separation. Our basic reasoning is that the ratio of horizontal inflow into the wetland depends on the amount of overall grid cell inflow $I_{\mathrm{gc}}$ and the wetland covered grid cell fraction $f_{\mathrm{w}}$. While a very small wetland will get almost no inflow and a grid cell size wetland will get it all, the associated relation in between these two extremes is not clear. Two simple approaches were tested for this relation: an exponential function (Eq. 7) and a tanh function (Eq. 8).

$I=I_{\mathrm{gc}} \times f_{w}^{z}$

$I=I_{\mathrm{gc}} \times \min \left[\left(\tanh \left(4 \times \pi \times\left(f_{\mathrm{w}}-0.5\right)\right)+1\right) \times 0.5,1.0\right]$

These functions can be interpreted as follows. Exponents $z<1$ in Eq. (7) results in a large ratio of inflow already for small wetlands meaning that wetlands are usually close to the rivers and store a considerable amount of water even while being small. For exponents $z>1$, the inflow ratio increase is shifted to large wetlands indicating that water flow would be confined to river channels and bypass the wetlands. The tanh function (Eq. 8) would indicate a tipping point meaning that below a certain wetland fraction the inflow is confined to the river channel but above this fraction rivers cannot bypass wetlands anymore and wetlands gain more water from the grid cell inflow. An optimisation method was used to find the best parametrization for the inflow partition based on the difference between simulated and observed river discharge (Eq. 11). We give more information about the optimisation in Sect. 2.4.

The horizontal outflow is computed following the linear reservoir approach (Singh, 1988); it is similar to the parametrization of river flow in the HD-Model (Hagemann and Dümenil, 1998). The outflow $O$ from the wetland surface water storage $S$ is given as

$O=\frac{S}{k}$, with

$k=\frac{\Delta x}{v}$

where $k$ is the retention time of the wetland which depends on the distance $\Delta x$ between the actual and the downstream grid cell and the water flow velocity $v$. In contrast to the river flow parametrization which uses a $k$ that is constant in time, the retention time of the wetland varies depending on its water level $h$ as well as on its extent via the mean slope $s$ within the wetland covered area. It is computed following the Manning-Strickler equation (e.g. Gioia and Bombardelli, 2001) as

$v=c \times h^{\frac{2}{3}} \times s^{\frac{1}{2}}$

with $c$ as the flow coefficient. There are a wide range of estimates for $c$ for different river types. However, for the application in the MPI-HM it is necessary to optimise this parameter (see Sect. 2.4) because in our formulation it accounts not only for the roughness of the river bed but also for the resolution of the model. Additionally, $c$ estimates are only available for rivers but not for wetlands.

As can be see from Eqs. (7) and (10), the horizontal flows have a non-linear dependency on the wetland extent. This feature is a prerequisite for the DWES (see Fig. 1). As only those wetlands can produce any horizontal outflow that have a surface water storage (Eq. 9) and water level (Eq. 10) larger than zero, the wetland dynamics calculation is therefore limited to inundated wetlands. However, wetlands without surface water are still considered in the water balance calculation.

Both, the vertical and the horizontal, water balance calculations are applied to the same wetland water storage. This shared storage allows for the representation of the most extreme ratios of vertical to horizontal fluxes, saturated wetlands and floodplains as well as the representation of inbetween wetlands. This restriction to a general model approach for all wetland types simplifies the scheme as the need to derive specific parameters sets for every type of surface water body is omitted. Indeed, considering our focus on hydrological processes and the global perspective of the approach, we argue that the different surface water bodies are very similar in that respect and mostly vary only in the relation of the different water fluxes in their water balance as well as their topographic conditions. Both aspects are explicitly accounted for in our approach. Being restricted to hydrological indices only, we also lack the means to classify our simulated water body fractions into different types of wetlands or even separate between wetlands and lakes. We kept the term "wetland" though as wetlands represent the largest fraction of surface water bodies on the land surface.

\subsection{Model optimisation}

The DWES is designed to work on the large scale rather than on process scale. Thus, it does not explicitly resolve the hydrological processes in wetlands. Instead, they have to be parametrized. Often these parameters need to be optimised to account for the model resolution as well as for simplifications in the equations. For our study the inflow scheme (Eqs. 7 and 8) together with the inflow exponent $z$ (Eq. 7), 
the flow velocity coefficient $c$ (Eq. 10) and the slope sensitivity $\kappa$ (Eq. 5) need to be optimised.

Usually, parameters are calibrated such that the model represents a quantity in best agreement with observations or theory. This is also done for most global scale wetland models (e.g. Kaplan, 2002; Gedney et al., 2004) to achieve a good agreement between simulated and observed wetland extent. However, global datasets of wetland extent are still very uncertain and disagree with each other considerably (Lehner and Döll, 2004; Frey and Smith, 2007). This is mostly due to the different methods that are used to derive wetland extent as well as the broad range in wetland definitions. The use of any of today's wetland observation data for parameter calibration would bias the model towards the distinct wetland definition and observation method used in that respective dataset and probably affect the model's ability to represent a realistic wetland distribution under different climatic conditions. For this reason, we decided not to use wetland observations directly as a calibration target. Instead, our optimisation aims for the minimization between model simulated and observed river discharge. River discharge data is more robust than wetland extent observations and available for longer time periods. As a test study revealed, the high sensitivity of river discharge to wetland extent, a realistic wetland extent representation by the MPI-HM would be a by-product of the river discharge based parameter optimisation. For this reason, climatologies of river discharge observations from the Global Runoff Data Centre (2011) were used as an optimisation target. Of course, river discharge data is not available for every model grid cell. Furthermore, it is a point measurement which is often difficult to compared to grid cell averages. However, the measured river discharge at a gauging station represents an integral over the horizontal water fluxes of the whole upstream area. Thus, a good agreement between simulated and observed river discharge depends on a valid choice of parameters for the whole river catchment. The optimisation is based on a selection of 96 river catchments. These catchments must contain at least 40 model grid cells and must have a similar size $( \pm 10 \%)$ in observations and model. Thus, only catchments are considered that can be represented by the MPI-HM with sufficient quality. Following the simplicity criteria of the MPI-HM, globally constant parameters are derived instead of grid cell values. While global values can not account for the vast diversity of wetland types, they are much more robust against outliers caused by errors in the observations or by processes which are not taken into account by the model.

In order to minimise the number of required model simulations and to provide optimal constraints for it, the optimisation was decomposed into two separate steps. In the first step, only the inflow scheme type and its exponent $z$ as well as the flow velocity coefficient $c$ are considered. While both parameters depend on the wetland extent, they feed back to it only indirectly via the water balance. Therefore, it is possible to substitute the dynamically calculated wetland extent with fixed wetland observations. This gives a realistic constraint to an otherwise free parameter (the slope sensitivity $\kappa$ ) and, thus, saves the third dimension in the parameter space. In order to minimise the impact of observation uncertainty and account for the range of wetland definitions, four different global wetland observation datasets were chosen as constraints. These are a satellite derived inundation dataset (SIND) (Prigent et al., 2001, 2007), the Global Lake and Wetland Database (GLWD) (Lehner and Döll, 2004), the Land Surface Parameter set 2 (LSP2) (Hagemann et al., 1999; Hagemann, 2002) and a wetland ecosystem map (MATT) (Matthews and Fung, 1987). The specific features of these datasets are discussed together with the model evaluation in Sect. 3.1. The parameter space of the inflow scheme type and exponent $z$ and $c$ was systematically sampled. For every sample, four simulations using the four wetland observations as constraints were conducted and the difference between simulated and observed river discharge was analysed. Deviations in the river discharge curves are not caused solely by the wetland parameters but also by the neglect of irrigation, river regulation and dams as well as biases in the forcing data. Furthermore, the observations themselves might have a considerable uncertainty (Di Baldassarre and Montanari, 2009) although most probably less than the global wetland observations. Consequently, only the peak flow month and the variance of river discharge as a measure for seasonality were taken into account. These are known to be sensitive to wetland influence (Bullock and Acreman, 2003). The absolute amount of discharge was neglected because it is more strongly influenced by precipitation forcing than by wetland processes. Peak flow month $P$ and the monthly variance VAR of river discharge were combined in a cost function $\gamma$ that evaluates the agreement between the observation obs and the simulation sim with a given pair of parameter values $z$ and $c$ for a river catchment $r$ as

$$
\begin{aligned}
\gamma(z, c, r) & =\left(\frac{\left|P_{\text {sim }}-P_{\text {obs }}\right|}{6}+1\right) \\
& \times\left(\frac{\left|\mathrm{VAR}_{\text {sim }}-\mathrm{VAR}_{\mathrm{obs}}\right|}{\mathrm{VAR}_{\text {sim }}+\mathrm{VAR}_{\mathrm{obs}}}+1\right) .
\end{aligned}
$$

The result of the cost value $\gamma(z, c, r)$ becomes smaller with decreasing differences between simulation and observation. For every simulation, $\gamma(z, c, r)$ was weighted by the wetland fraction for the respective catchment and averaged over all 96 river catchments as shown in Eq. (12):

$\gamma(z, c)=\sum_{1}^{r}\left(\gamma(z, c, r) \times \frac{f_{\mathrm{W}}(r) \times A(r)}{\sum_{1}^{r} f_{\mathrm{W}}(r) \times A(r)}\right)$

where $A(r)$ is the area of the river catchment and $f_{\mathrm{w}(\mathrm{r})}$ is its observed wetland fraction. The average cost value of all four simulation series indicates the best parameter values and their standard deviation give a measure how well the simulation results agree on this. These results are shown in Fig. 4. Generally, the tanh inflow scheme seems to be less 
optimal than the exponential inflow scheme. The most robust results are found for large exponents of the exponential inflow scheme and a low discharge coefficient (Fig. 4, left). However, the cost value is quite high indicating that all simulations agree that this parameter combination lead to a decreased model skill. The lowest cost value (1.67) is found for an inflow exponent $z=2$ and a discharge coefficient $c=1 \mathrm{~m}^{1 / 3} \mathrm{~s}^{-1}$. At this point, the robustness of the result is still reasonable $(\sigma=0.05)$. Two more refinements around this point were done. The medium sampling resolution showed the lowest cost value (1.66) at $z=1.3 \overline{3}$ and $c=$ $2.0 \mathrm{~m}^{1 / 3} \mathrm{~s}^{-1}$ but a slight decrease in robustness $(\sigma=0.06)$. Eventually, the best results were found in the fine resolution sampling for $z=2$ and $c=1.1 \mathrm{~m}^{1 / 3} \mathrm{~s}^{-1}$ with a cost value of 1.66 and $\sigma=0.05$.

Next, the slope sensitivity $\kappa$ was optimised. As $\kappa$ is directly included in the dynamical wetland extent calculation, wetland observations cannot be prescribed during this optimisation step. However, the optimised values for $z$ and $c$ are now used in the model and give optimal constrains for the water balance calculation. Furthermore, a set of optimised simulations with static wetland extent is available from the first optimisation step. As two model simulations are better comparable to each other than to observations, we now use their simulated river discharge as optimisation target. Thus, we know that all differences between the river discharge curves are solely caused by the parametrization of $\kappa$ and model deficits like the neglect of human impacts, already existing model parameterizations or effects of model resolution have no effect on the analysis. Consequently, the analysis of river discharge differences is not limited to peak flow month and seasonality anymore. Instead, the normalized root mean square error (NRMSE) was calculated between the optimised river discharge with prescribed wetland extent and a series of 20 MPI-HM simulations with systematically varied $\kappa$. Starting with large values for $\kappa$ the decrease in $f_{\mathrm{w}}$ weighted average NRMSE levelled off at $\kappa=1$. As no further simulation improvement was achieved with values of $\kappa<1$, this value was accepted as optimal $\kappa$ at this model resolution.

As final step of the optimisation, it was investigated whether the MPI-HM with optimised wetland parameters is able to simulate river discharge in a better way than a MPIHM control simulation without any wetland representation. Again, we applied the cost function (see Eq. 11) to compare the climatologies of simulated river discharge with the observed river discharge from the GRDC. For most catchments, the change in simulation error ranges within $-8 \%$ and $2 \%$ with extremes up to $-45 \%$ and $61 \%$. No significant correlation of model improvement with the catchment's simulated wetland fraction or area is found. However, the strongest influence of the DWES is evident for rivers with a large catchment and a mean simulated wetland area greater than $1000 \mathrm{~km}^{2}$. Discharge representations of rivers like Amazon and $\mathrm{Ob}$ are usually closer to observations in terms of peak flow month and seasonality than smaller catchments.
However, other large catchments, e.g. Mackenzie and Mississippi are simulated with less agreement. On average, there is only a small improvement of the discharge simulation. On the one hand this is indicating that the restriction to global parameters does not account for the vast diversity of different wetland types. Thus, it might be necessary to develop more specific parameters for different catchments in future model versions. On the other hand, we found no strong changes in artificially influenced river catchments like Nile, Amu Darya and Rhine, which are either used for irrigation or are strongly regulated. Human influences are not captured by the MPI$\mathrm{HM}$ and therefore river discharge in those catchments cannot be simulated correctly. Here, the application of global parameters prevents the MPI-HM from counteracting simulation errors that are not connected to wetlands. Thus, a thorough model evaluation is necessary to investigate whether the minor improvement in river discharge can sufficiently constrain the wetland parameter optimisation and, thus, yield a satisfying representation of the large scale wetland distribution.

\section{Model evaluation}

In order to evaluate the DWES, its results are compared to global observations of wetland extent and their seasonality. The analyses are mostly focused on large scale structures. Additionally, the representation of water bodies at grid cell scale is investigated to learn about the limitations of the DWES. Similar to the optimisation procedure, the MPI-HM uses the Watch Forcing Data (Weedon et al., 2011) from 1958-1999 as climate forcing for the evaluation simulations. Due to model spin-up, only the years 1963-1999 are considered in the evaluation.

\subsection{Global wetland distribution}

Starting with the global scale analysis, we compare the simulated wetland fraction with four datasets of global wetland and inundation observations. While these datasets have already been used as boundary conditions in the optimisation procedure, the MPI-HM is not calibrated to match them. Thus, they can still be applied as an independent basis for the evaluation. However, it has to be noted that the observations are not directly comparable to our simulation results as well as between one another because of the different wetland definitions which they are based on. Thus, we first will provide some more details about the observation datasets.

The oldest wetland dataset that is used in this study is the wetland ecosystem map (MATT) by Matthews and Fung (1987) with a original resolution of $1^{\circ}$. It contains wetlands identified by their vegetation, soil properties and grid cell inundation fraction, based on field data as well as on aerial photography. Five wetland types are distinguished, namely forested bogs, non-forested bogs, forested swamps, non-forested swamps and alluvial wetlands. 

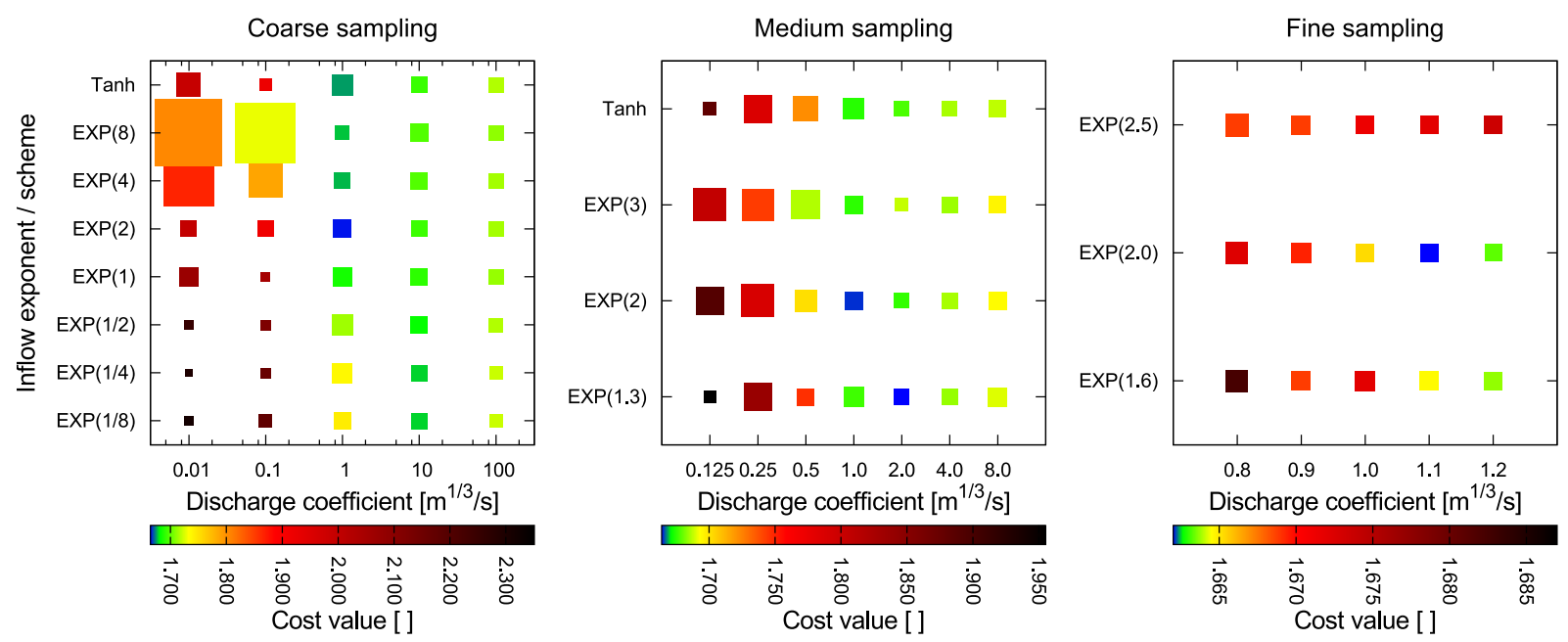

Fig. 4. Optimisation results for MPI-HM simulations with prescribed wetland extent. The color indicates the skill of the simulation in respect to river discharge observations (low values are best) and the size of the square indicates its robustness (inverse standard deviation, large squares are most robust). The sampling of parameter space of discharge coefficient and inflow parametrization is gradually refined from left to right.

The Land Surface Parameter set 2 (LSP2) was compiled by Hagemann et al. (1999) and revised by Hagemann (2002). It includes lakes as well as wetlands, and it is derived from the Global Land Cover Characteristics Data Base (US Geological Survey, 2001), which was generated using satellite data with a resolution of $1 \mathrm{~km}$. While lakes are easily identified, the authors stated an increased uncertainty in the distribution and extent of the wetland fraction. Lehner and Döll (2004) combined several existing maps and data bases into the Global Lake and Wetland Database (GLWD). It provides the maximum extent of lakes, reservoirs, rivers and wetlands at a resolution of $30^{\prime \prime}$ divided into 12 classes. Finally, a pure satellite product is taken into account which represents surface water covered areas on a monthly basis (Prigent et al., 2001, 2007; Papa et al., 2010). The satellite derived inundation dataset (SIND) is based on a $12 \mathrm{yr}$ time series originating from different satellites using active and passive microwave measurements as well as visible and near-infrared imagery. From this data Prigent et al. $(2001,2007)$ and Papa et al. (2010) calculated inundated area fractions for $0.25^{\circ}$ grid cells. While the authors claim that their multi-satellite approach accounts for open water even under dense canopy, snow covered areas were masked out to avoid any confusion between open water and snow pack. All datasets are displayed in the upper and middle panels of Fig. 5.

The GLWD, LSP2 and MATT include no information about seasonal variations in wetland distribution, but provide their maximum observed extent only. Thus, the maximum climatological extent of the MPI-HM results and the SIND observation had to be computed prior to the analysis. Table 1 gives an overview about the simulated and the observed wetland cover fractions for every continent. In all regions except Asia, the largest wetland fraction estimate is produced by the MPI-HM. It strongly overestimates the wetland extent for South America and Africa (27.5\% and $10.1 \%$, respectively) compared to the observations. However, for North America the GLWD indicates a similar extensive wetland cover as the MPI-HM (around 18.1\%) and also agrees well for Asia $(6.1 \%)$. For Europe, a wetland extent of $8.3 \%$ is simulated which is close to the estimate of the MATT dataset. With $4.3 \%$ coverage, the Australian wetland extent is simulated about $1 \%$ larger than seen in the GLWD. Globally, the MPI-HM simulates a wetland fraction of about $12 \%$, followed by the GLWD with $8.1 \%$. Table 1 also gives information about the large variations in the wetland observations. For North and South America the GLWD indicate a 3 times larger wetland cover than the MATT and LSP2, respectively. Also on global scale, the estimates range from $3.7 \%$ (MATT) to $8.1 \%$ (GLWD) and thus demonstrate the large uncertainty in observations.

When analysing the spatial distribution of wetlands on the land surface, the observations display some disagreement in the exact location of wetlands. However, on a large scale, a pattern can be found that is mostly shared by all four observations. All datasets show most wetlands in the high northern latitudes. They are located especially in Northern America and Northern Europe as well as in Western and Eastern Siberia. Furthermore, wetlands occur in the tropical regions of South America and Africa but there the observations differ distinctively in the absolute extent and the exact location of the wetlands. Two of the datasets also indicate extensive wetlands in Southeastern Asia which are not shown in the other observations. The wetland observations together with the simulated wetland distribution are displayed in Fig. 5. Figure 5 demonstrates that the MPI-HM generated wetland distribution shows a similar large scale 


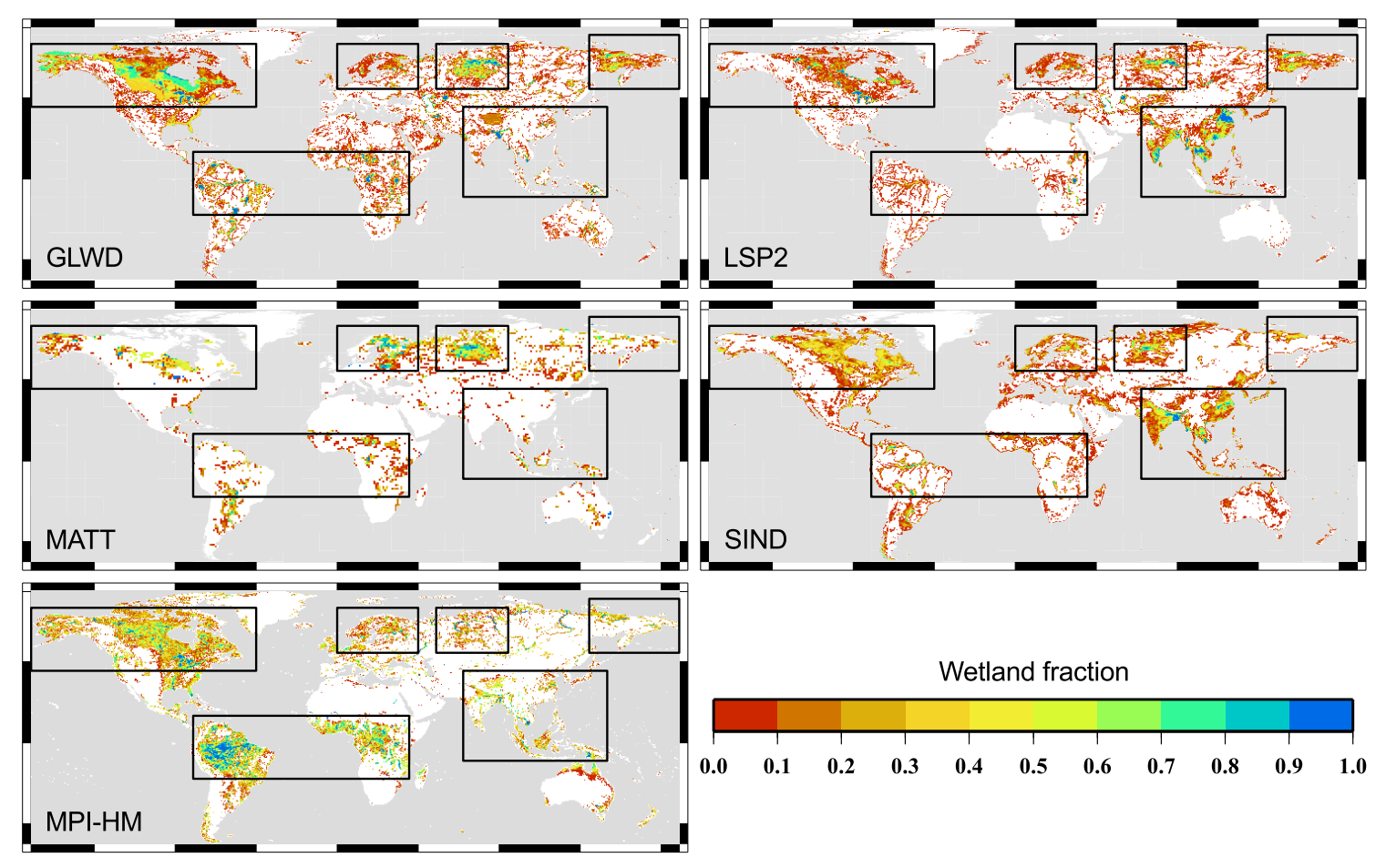

Fig. 5. Observed (top, middle) and simulated (bottom) maximum wetland distribution. The colors indicate the wetland fraction for every $0.5^{\circ}$ grid cell. The black boxes highlight regions of pronounced wetland occurrence.

Table 1. Simulated and observed maximal wetland cover for different continents in percent of the global land surface without Antarctica.

\begin{tabular}{lrrrrr}
\hline Continent & MPI-HM & GLWD & LSP2 & MATT & SIND \\
\hline North America & 18.11 & 16.72 & 5.59 & 4.62 & 9.29 \\
South America & 27.46 & 9.25 & 2.23 & 3.86 & 6.23 \\
Europa & 8.31 & 4.55 & 4.18 & 7.40 & 5.84 \\
Africa & 10.13 & 5.11 & 1.49 & 2.34 & 2.54 \\
Asia & 6.13 & 6.98 & 9.34 & 3.53 & 7.82 \\
Australia & 4.32 & 3.14 & 0.27 & 2.14 & 2.20 \\
\hline Global & 11.92 & 8.11 & 5.09 & 3.71 & 6.20 \\
\hline
\end{tabular}

pattern as the observations. The best agreement is visible for North America where the pattern of wetland distribution is well matched. However, the maximum wetland extent exceeds the range of observed values. The wetlands in the north of Europe are well represented and their extent is similar to the observations. Also the Siberian wetland regions are reproduced by the MPI-HM but especially the East Siberian wetland cluster is underestimated. Likewise, too few wetlands are simulated for Southeastern Asia in China and the region between Vietnam and Myanmar if compared to the LSP2 and SIND. In contrast, the GLWD and MATT display less wetlands than the MPI-HM in this area. In the Southern Hemisphere the simulated wetlands concentrate in the Amazon and Congo catchments. While this location is generally confirmed by the observations, the overall extent is strongly overestimated by the model. Overall, these simulation results demonstrate that the DWES is able to reproduce the large scale wetland patterns. Although there are differences in the extent of the wetland clusters, these differences are mostly in the same magnitude as the differences among the wetland observations themselves. However, the model fails to represent a realistic wetland extent for the tropical parts of South America and Africa.

An analysis of the zonal mean wetland fraction (see Fig. 6, top) reveals one wide peak in wetland occurrence around $60^{\circ} \mathrm{N}$ and a second, narrow peak just south of the equator. Again, there are distinct differences between the four observational datasets with deviations in zonal wetland extent up to $10 \%$ of the $0.5^{\circ} \times 0.5^{\circ}$ sized grid cell area. In the Northern Hemisphere the simulated wetland fractions follow the 


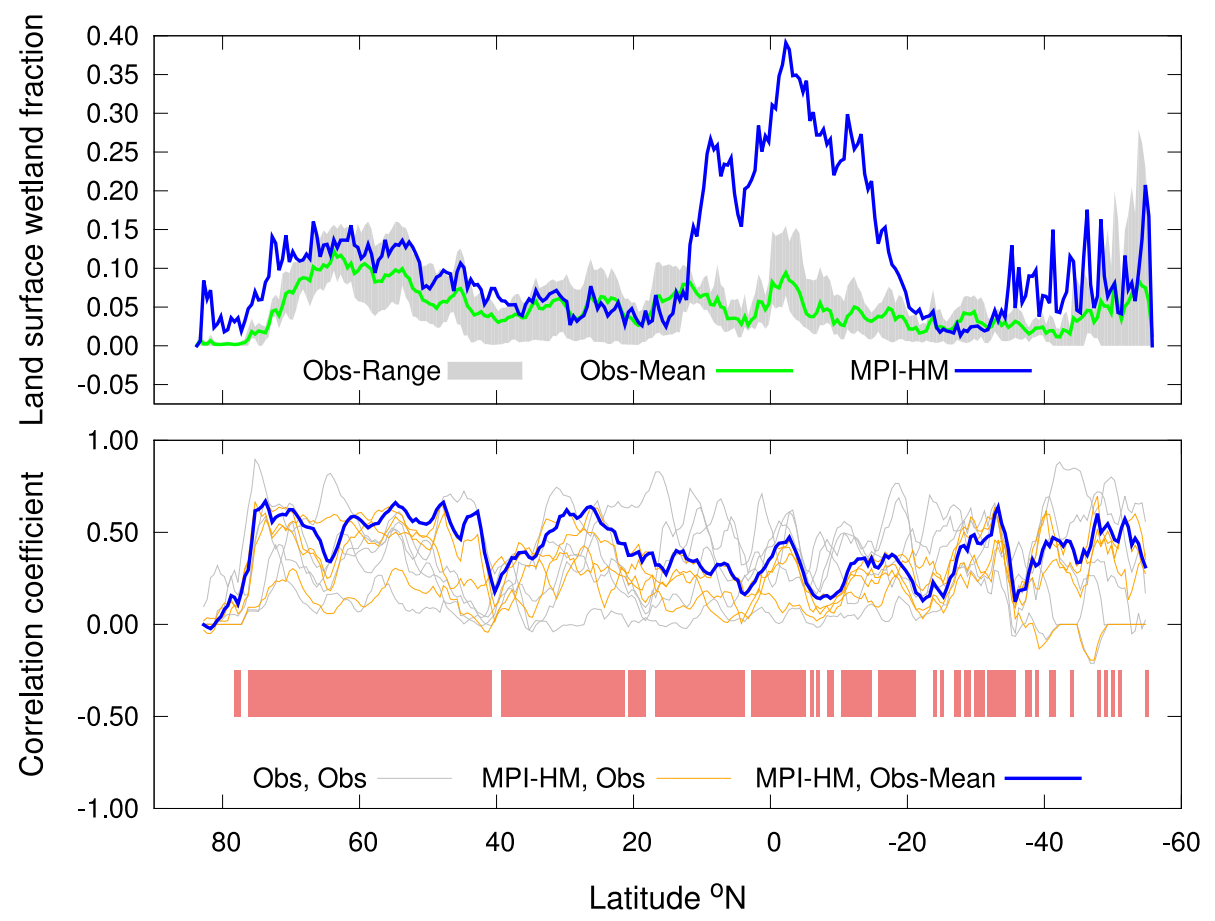

Fig. 6. Top: zonal means of land surface wetland fraction. The grey area indicates the range of the observation datasets, the green curve shows their mean extent and the blue curve shows wetland fractions as simulated by the MPI-HM (blue). Bottom: zonal correlation between the MPI-HM wetland extent and the mean of observations (blue), between the MPI-HM wetland extent and the four observation datasets (orange) and between the observations themselves (grey). Displayed are running means over 2.5 latitudes. The red boxes indicate latitudes where the correlation significance level between the MPI-HM results and mean extent of the observations is above $95 \%$.

shape of the observation mean curve and is mostly found in the upper part of the observational range. Similar to the observations, the largest wetland fractions are computed between $40^{\circ}$ and $70^{\circ} \mathrm{N}$. However, the second peak between $10^{\circ} \mathrm{N}$ and $20^{\circ} \mathrm{S}$ is overestimated by the MPI-HM by a factor of almost four compared to the observation mean. Further south, the simulated zonal mean wetland extent first drops to the range of observed values but shows a very noisy signal due to the small land surface fraction in these latitudes.

We also investigate the spatial agreement between simulation and observation. Figure 6 (bottom) shows the linear correlation coefficient of the wetland fractions along the latitudes for the different wetland fraction data. Considering first the correlation between the observation datasets themselves, the coefficients lie mostly between 0 and 0.5 . At some latitudes, e.g. between $40^{\circ}$ and $50^{\circ} \mathrm{N}$ almost no correlation is seen, whereas at other latitudes some observational datasets are highly correlated. The noisy signals indicate that the agreement between the observations varies strongly from latitude to latitude and there is no combination of observation datasets that show a high correlation over a larger latitude band. The figure also demonstrates that the correlation coefficients between simulation and observations lie in the same range as those between the observations. Focusing on the correlation between the simulation and the mean of the observations, the highest correlation coefficient of about 0.5 is found for the high northern latitudes while the lowest correlations concentrate directly south of the equator. The correlation is significant for the majority of latitudes.

\subsection{Seasonal variations in wetland extent}

Beside the simulation of maximum wetland extent, the variation of wetland extent is another key aspect of our study. These variations are a measure for the response of the MPIHM to changes in climatic forcing and its analysis shows whether the hydrological cycle of wetlands is represented in the MPI-HM in sufficient detail. However, long-term time series, about year to year variability in wetlands, are rare on a global scale. Furthermore, their amplitude is exceeded by the amplitude of seasonal variations in the MPI-HM simulations. Thus, we focus our analysis on seasonal variations rather than year to year changes. Concerning the model accuracy and its high sensitivity to short-term climatic variations we argue that both are better demonstrated by the model's representation of the seasonal wetland extent variations.

The MPI-HM simulated wetland extent variations are displayed in Fig. 7. Throughout the year, the wetland extent changes up to $30 \%$ in grid cell area. The figure also demonstrates the effects of two large scale processes that are represented by the simulation. In the northern high latitudes 


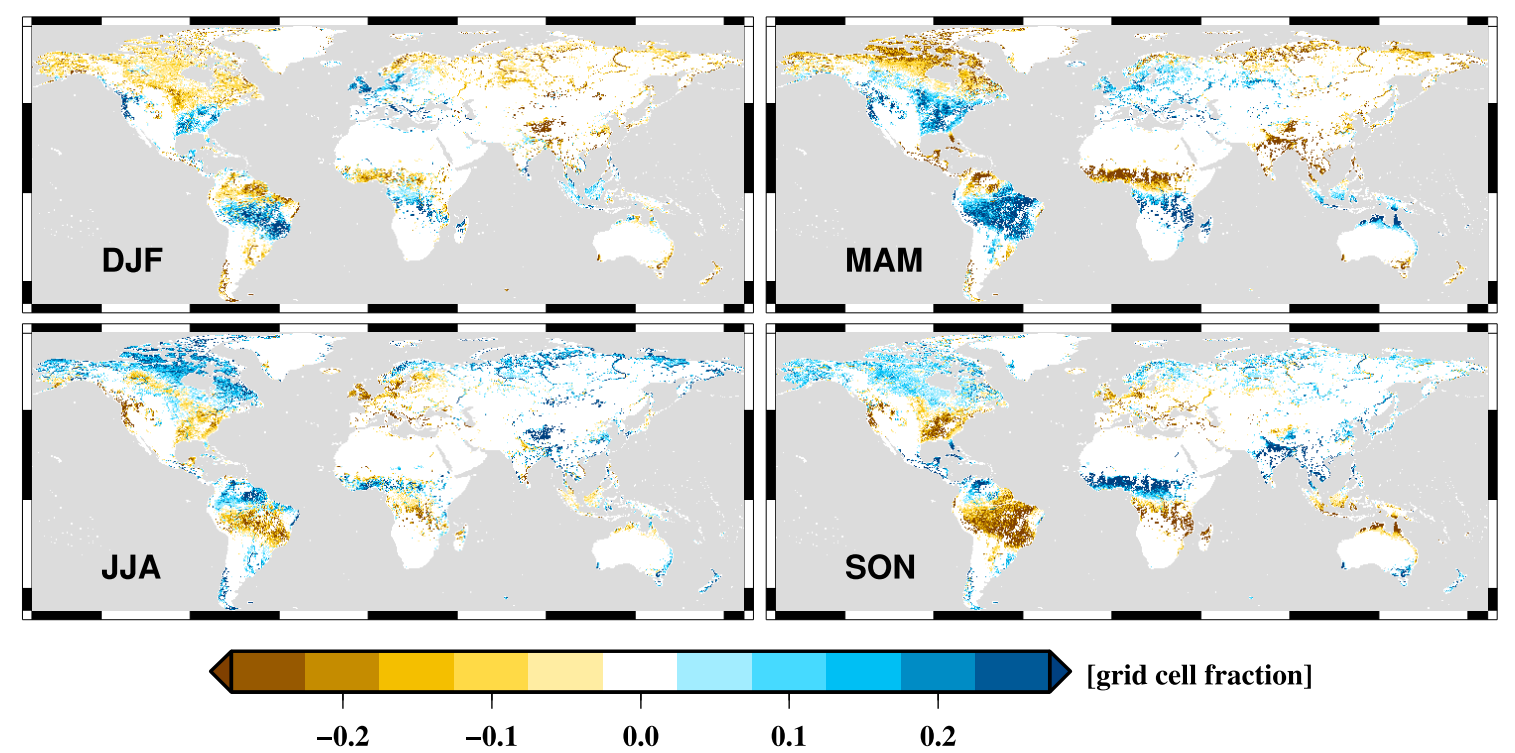

Fig. 7. Deviation of the wetland fraction from its yearly mean for all seasons as simulated by the MPI-HM.

the wetland fraction decreases during DJF. It subsequently increases again starting from the south during MAM and reaching the far north in JJA. This behaviour reflects the decreased wetland inflow during the cold season and the increased inflow due to snowmelt. In the tropics the wetland extent follows the rainy and dry seasons which are caused by the movement of the Intertropical Convergence Zone. Consequentially, the MPI-HM computes decreased wetland fractions north of the equator in DJF and increased wetland fractions south of it. This pattern is mirrored during JJA.

The model evaluation is restricted to one observational dataset, the SIND, because it is currently the only global dataset with monthly values of inundated area. Figure 8 displays the climatologies of simulated and observed wetland extent for different latitude bands. For the high latitudes larger than $60^{\circ}$, the MPI-HM simulates decreased wetland fractions during winter and a strong peak due to snowmelt in June. Furthermore, a second wetland extent maximum is visible for autumn. However, the SIND shows only a single peak and no wetlands during winter because satellites are not able to identify wetlands below snow cover. Thus, snow covered grid cells have been masked out in the observational data (Papa et al., 2010). After applying the SIND snow mask for the simulated wetland fractions, both datasets agree well in the timing of the wetland extent variations. A similar effect is seen for the mid latitudes (between $23.5^{\circ}$ and $60^{\circ}$ ) where the application of the snow mask results in a good agreement between simulated and observed wetland extent seasonality, too. In the low latitudes (less than $23.5^{\circ}$ ) the snow mask has no significant effect on the simulation results. Here, the wetland seasonality agrees mostly well with the SIND in timing as well as in the relative amplitude of the variations.

\subsection{Results on grid cell scale}

In order to learn about the limitations of the DWES, we also analyse the results on the scale of just a few grid cells. In this analysis we do not expect to represent the observed wetland fractions perfectly but to learn under which conditions the model succeeds or fails on the grid cell scale.

First, we focus on the differences between the maximum MPI-HM wetland fraction and the observation datasets. In order to increase the robustness of the analysis, an average wetland extent is calculated for every grid cell based on the grid cell itself and its 8 neighbouring grid cells. Thus, the data is smoothed and spatial offsets of just one grid cell are neglected. The relative difference is calculated as $\left(f_{\mathrm{w}, \mathrm{sim}}-f_{\mathrm{w}, \mathrm{obs}}\right) /\left(f_{\mathrm{w}, \mathrm{sim}}+f_{\mathrm{w}, \mathrm{obs}}\right)$ and displayed in Fig. 9 (left). It ranges from -1 for observed wetlands that are not simulated by the MPI-HM to 1 for simulated wetlands that are not seen in the observations. For all dataset combinations, the same three steps are found in the cumulative difference distribution albeit with varying frequencies. The steps occur at $-1,0$ and 1 . This indicates that for $10 \%$ (GLWD) to $30 \%$ (MATT) of grid cells the MPI-HM represent wetland fractions with a similar extent while for the remaining grid cells either the observations or the simulation do not show any wetlands at all. Only a small number of grid cells are computed with differences in between these extremes. Analysing the spatial distribution of relative differences we find that values around zero occur mostly in very dry regions. There, the MPI-HM and the observation agree on the absence of any wetlands. Values of -1 occur mostly for grid cells with a very low wetland fraction in observations while large values up to 1 are most often found in the tropical regions and the high northern latitudes. In the analysis 

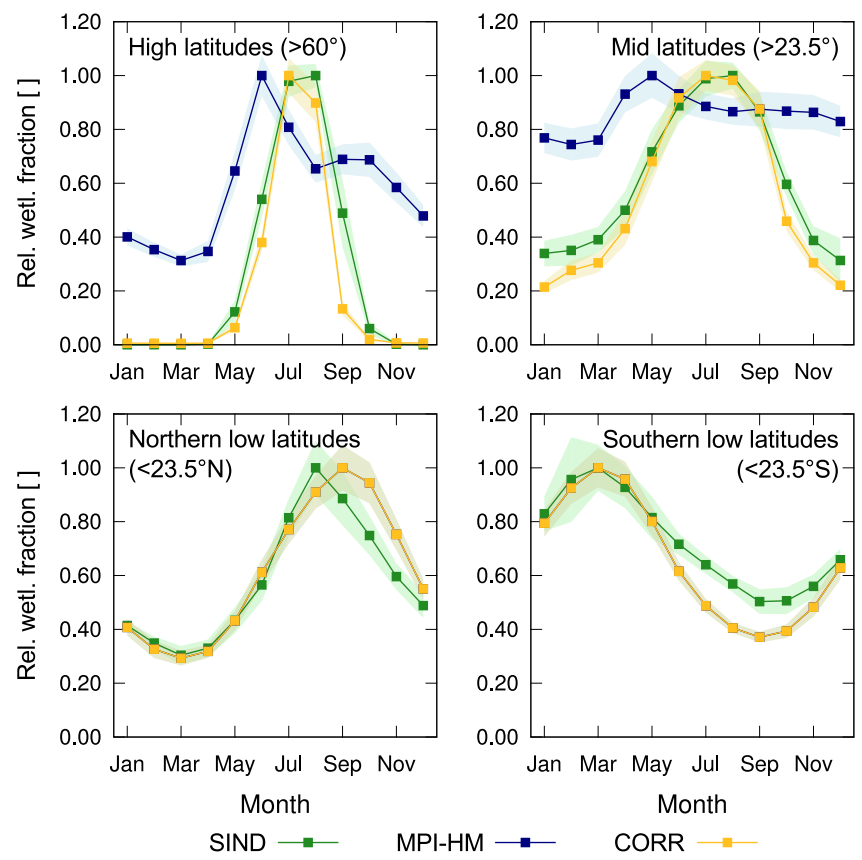

Fig. 8. Seasonality of wetland extent relative to its maximum for different latitude bands. The green color indicates the SIND observations, the blue the MPI-HM results and the yellow line represents the MPI-HM results corrected with the snow mask. For low latitudes the yellow curve lies on top of the blue because the snow mask has no significant impact on the wetland fraction in these regions. The shaded areas indicate the standard deviation.

of absolute differences cumulative frequency (see Fig. 9, right), the steepest step (about $55 \%$ of all grid cells) occurs for wetland fraction differences around zero. Again, all dry regions are included in this peak but also most of the areas where either MPI-HM or observations indicate wetlands. This demonstrates that the large relative differences are often related to very small absolute differences. The absolute differences of the remaining grid cells are more often positive than negative, indicating that the MPI-HM more often overestimates wetland extent than underestimating it. For the relative as well as the absolute differences, these results are similar if the observation datasets are compared to each other instead to the MPI-HM results. Testing the correlation between the grid cell wetland fractions we find that the MPI-HM wetland fractions correlates significantly but weakly with the observation. The correlation coefficient spreads from 0.20 (MATT) to 0.44 (GLWD). This is in the same range as the observations correlate with each other. The minimum correlation coefficient between observations is 0.12 (LSP2 and MATT) and the maximum lies at 0.50 (GLWD and MATT).

Second, we enhance the analysis of seasonal variations by calculating the temporal correlation between simulation and observation (Fig. 10) for every grid cell. Similar to the first analysis, we use a 9 grid cell average as basis for the correlation. Additionally, the snow mask is applied. For most of the large scale wetland clusters, a good temporal correlation is achieved, but in between those areas pronounced regions of insignificant correlations are found. Examples for these regions are wide parts of Europe as well as some areas in South America, Africa and Australia. Additionally, insignificant correlations occur north of $60^{\circ} \mathrm{N}$. Investigating the reasons for this pattern, we find a strong impact of the snow mask. As its application decreases the number of months that can be used in the correlation analysis, the correlation becomes less significant. Occasionally, the significance is biased towards higher values for larger wetlands. However, the latter feature is not a robust result. Neglecting all insignificant correlations, a global mean correlation coefficient of 0.70 is computed.

Additionally, in reference to the variations of wetland extent, variations in wetland water level are also an important indicator of model quality. However, long-term time series of wetland water level exist only for very few locations and are often interrupted during winter. Thus, we use satellite observed lake level data as a substitute for wetland observations. While the MPI-HM does not simulate lakes explicitly, they are included in our definition of wetlands (see Sect. 2.3). Of course, lake level data accounts only for a small part of the simulated surface water. Thus, we restrict our analysis on the correlation of simulated and observed seasonality in the water levels. For this analysis, we assume the observed lake level variations to be representative for all surface water bodies within a grid cell size area, because two of their major water sources, rainfall and inflow from upstream areas, are often the same for both water bodies. We also compare the overall range of variability in observed lakes and simulated wetlands, but only to learn about the limitations of the DWES. The Global Reservoir and Lake Monitor (GRLM, 2011) provides data on lake level variations collected by several satellites. In our analysis we used data for 79 lakes for the period between 1992 and 2002. Figure 11 displays the linear correlation coefficient between the observed and simulated monthly climatologies of water level variations for 79 lakes. For 12 lakes no surface water occurs in the model and 27 lakes do not show any significant correlation above the $90 \%$ confidence level. For 24 lakes the observation correlate very well with the simulation with coefficients above 0.8 . The correlation of another 14 lakes is at least 0.5 while the remaining three lakes show a significant negative correlation. Investigating the reasons for the insignificant correlations, we find that insignificant results occur preferably for lakes with a mean simulated water throughflow below $300 \mathrm{~m}^{3} \mathrm{~s}^{-1}$. As the water throughflow is connected to the size of the respective upstream catchment, a similar effect is seen there, too. Insignificant correlations are mostly found for catchments smaller than $0.2 \times 10^{6} \mathrm{~km}^{2}$ while significant results dominate for larger upstream catchments. While the timing of intra-annual water level dynamics is simulated well for about one third of the lakes, the DWES underestimates the range of these variation for almost every location. Analysing 

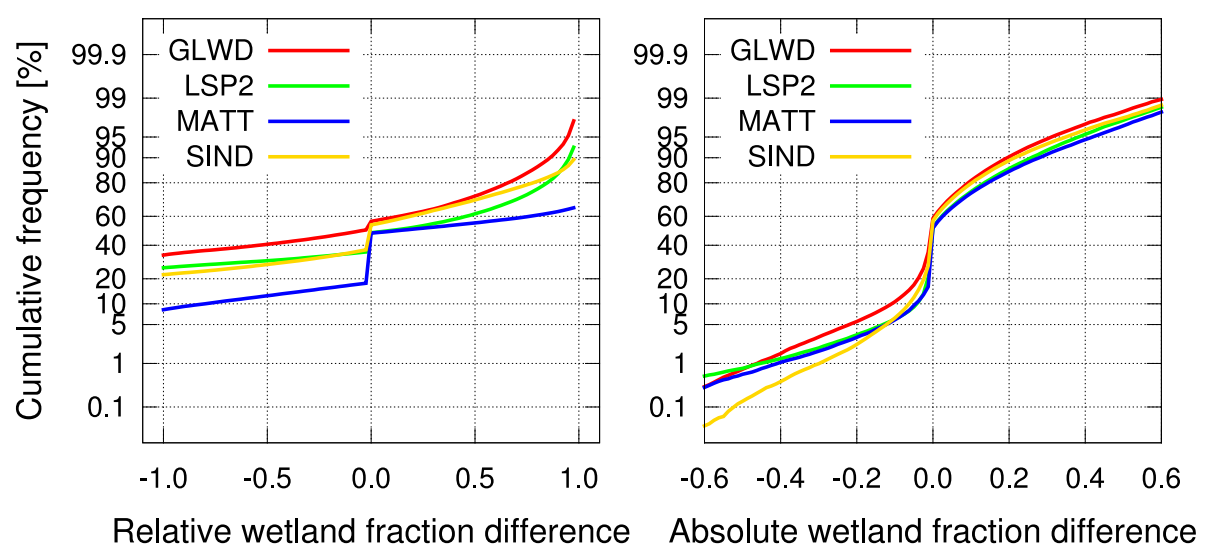

Fig. 9. Cumulative distributions of relative (left) and absolute (right) wetland extent difference at grid cell scale between the MPI-HM simulation and observations.

this model behaviour, we find good agreements only for those lakes which have a low variability in the observations or are simulated with a large grid cell fraction. In these cases, the water throughflow does not play any significant role.

\section{Discussion}

In terms of large scale patterns, the DWES represents the wetland distribution successfully. However, deficits in computation of the wetland extent have been revealed during the evaluation and need to be discussed. Another important question is how the representation of wetlands in the MPI-HM might affect hydrological components in the climate system, e.g. due to enhanced ET. As our study is conducted using a global hydrological model with prescribed climatic forcing, we cannot directly investigate any large scale hydrological feedbacks of wetlands. Still, we can evaluate whether wetlands have the potential to impact the land surface hydrology significantly.

\subsection{Wetland impact on ET and runoff}

There are a number of possibilities how wetlands might influence the Earth system. Several studies focus on changes in atmospheric methane concentration (e.g. Gedney et al., 2004; Finkelstein and Cowling, 2011) and its effect on mean surface temperature as a result of the change in radiative forcing. Coe and Bonan (1997) simulated the influence of surface water on Mid-Holocene climate conditions and found an increase in net surface radiation, latent heat and humidity as well as an decrease in the sensible heat flux. These changes lead to a cooling of the atmosphere and an alteration of the atmospheric flows resulting in changes in the regional precipitation patterns. Dadson et al. (2010) and Taylor (2010) concentrated on the Niger inland delta. The authors related the seasonal inundation in this region with enhanced evaporation and an increase in cloud cover and convection. In our study we concentrate on the impact of wetlands on ET and runoff. Here, we compare the results of a MPI-HM simulation using the DWES to a MPI-HM control simulation without any wetland representation.

In the MPI-HM, the only connection from wetlands to the atmosphere is via the ET. We find that the simulation of wetlands increases the annual ET by $4.5 \mathrm{~mm}$ on average over the global land surface without Antarctica. The largest ET increase occurs during the summer months. For most of the land surface, this ET anomaly is below $0.1 \mathrm{mmd}^{-1}$. However, regionally much stronger effects occur, for instance, in high latitudes of North America and Eastern Siberia. Due to open water in the simulated wetlands, they almost evaporate at the potential rate resulting in ET anomalies exceeding $1.0 \mathrm{~mm} \mathrm{~d}^{-1}(\approx 25 \%)$ during the summer months. In contrast, small negative ET anomalies are simulated during dry spells for some grid cells in equatorial regions. This effect is related to a technical issue in the model. In contrast to the land surface, the wetland fraction is simulated without any canopy storage because its ET is already at maximum as long as surface water exists. In some cases, the open water surfaces may vanish completely during the summer resulting in decreased ET. ET does not reach its maximum value, before the soil is saturated again. While soil moisture is similarly low in the control simulation, its canopy storage reacts much faster to precipitation events and may allow for short-term high ET responses. However, this effect occurs only sporadically and does not effect the overall ET increase significantly.

Additionally, runoff is decreased due to the increased land surface storage capacity provided by the wetlands. Runoff that entered the river via overland flow in the MPI-HM control version, now resides in the wetland reservoir and is slowly released into downstream grid cells. In the mean time, it can potentially evaporate again. The surface runoff shows negative anomalies with mean values up to $-2 \mathrm{mmd}^{-1}$ in wetland dominated grid cells. The mean drainage declines by up to $-0.5 \mathrm{mmd}^{-1}$ because wetland soils are parametrized 

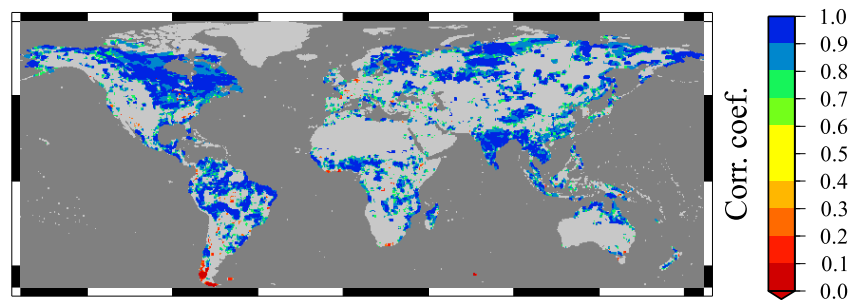

Fig. 10. Correlation coefficient of the temporal correlation between SIND and MPI-HM wetland extent climatologies. Only correlation with a significance higher than $90 \%$ are shown.

with a lower hydraulic conductivity. In spite of this, a positive drainage anomaly is found in wetland regions that are dominated by river flows. In the MPI-HM control version, water that once entered the river routing scheme is not available to the land surface anymore but flows directly into the ocean via the river network. However, the DWES allows for the recharge of wetlands by river flow and thus ET and drainage can be increased in downstream grid cells. Conclusively, the increase in drainage is not so much a result of the wetland simulation but rather enabled by the coupling between the horizontal and vertical water flows. Although positive drainage anomalies are just around $0.2 \mathrm{mmd}^{-1}$, they partly contribute to an increase of river flow in some catchments (see Sect. 4.2).

After the spin-up phase of the model, the DWES has no strong impact on the water storages of the MPI-HM. The changes in snow water equivalent, skin reservoir and average soil moisture content are below $0.01 \mathrm{mma}^{-1}$. The only storage that shows a trend in its content is the surface water storage. During the simulation period, its average increase is about $0.15 \mathrm{mma}^{-1}$.

\subsection{Wetland impact on river discharge}

Focusing on a selection of about 96 major river catchments, we find that almost all of them are sensitive to changes in wetland extent. In most cases, the simulated mean river discharge decreases in the presence of wetlands. Most catchments only experience a small decrease up to $5 \%$ of the annual discharge but also large changes up to $25 \%$ decrease occur. Similar effects are also apparent in the discharge seasonality. Comparing the variance of river discharge, the majority of catchments reveals a decrease between $0 \%$ and $45 \%$ with a maximum decrease of $90 \%$. Additionally, the peak flow is delayed when the DWES was active. For most catchments this delay is less than one month. These changes can be explained with the additional wetland water reservoir and its outflow parametrization. Due to its longer retention time (see Sect. 2) water release from the wetland reservoir is slower than from the river reservoir. Thus, the flow peak is decomposed in a fast and a slow component. The main peak is delayed until the superposition of both components reaches its

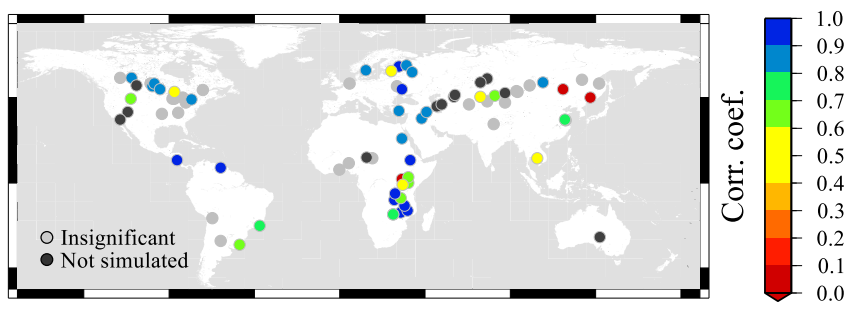

Fig. 11. Map of correlation coefficients in lake level climatologies between the MPI-HM simulation and GRLM observation. Light grey points indicate insignificant correlations and dark grey points indicate locations where no surface water body was simulated by the MPI-HM.

maximum. Additionally, the variation in river flow decreases because the wetland reservoir stores peak flow water and releases it after the flood event. In contrast, the overall decrease in river flow occurs due to the interactive coupling between the vertical and horizontal water balance sub-models. In this MPI-HM setup, water that is stored in the wetland reservoir is able to evaporate thereby reducing river discharge. These processes are also reported for most observed wetlands (Bullock and Acreman, 2003).

About seven catchments show the opposite reaction to the presence of wetlands. Increased mean flow and seasonality are evident in these catchments but no earlier peak flows can be recognized. The strongest increases are up to $20 \%$ for the mean flow and up to $40 \%$ for the seasonal variations. Examples for these exceptions are the catchments of the Blue Nile, the Sao Francisco and the Colorado River. They are located in regions where either wetlands are simulated with a large extent and a considerable water turnover or steep slope conditions prevail that facilitate fast water transport. In these catchments, water is transported more efficiently in the wetlands than via overlandflow. Together with the positive drainage anomaly, the bypass of overland flow causes locally increased river discharge. This behaviour is confirmed by Bullock and Acreman (2003) who reported on similar observations in some headwater wetlands.

In summary, about $530 \mathrm{~km}^{3} \mathrm{a}^{-1}$ less water reach the oceans than in the control simulation. This decrease balances most of the ET increase of $670 \mathrm{~km}^{3} \mathrm{a}^{-1}$. As the inflow decline is just about $1 \%$ of the overall simulated ocean inflow, we do not expect any significant influence on the ocean in terms of hydrology. However, the decline might have implications for the nutrient or sediment transport into the ocean.

\subsection{Limitations of the DWES}

The evaluation of MPI-HM results demonstrated distinct differences between the wetland extent in the MPI-HM generated and the observed datasets. While some of these differences might be related to uncertainties in the observations, most stem from either the difference in wetland 
definition or the application of a general approach for different wetland types.

The most obvious deficit in the MPI-HM is its strong overestimation of tropical wetland extent. For this region, Figs. 5 and 6 indicate an about four times larger wetland extent in the MPI-HM than stated in all four observation datasets. It is obvious that in the model too much water is available on the land surface indicating either a wet bias in the precipitation forcing, a too low PET or too low horizontal outflow from the respective basins. Precipitation and PET are part of the prescribed climate forcing. While precipitation is directly included in the WFD, PET is computed based on the Penman-Monteith equation for reference ET using meteorological variables of the WFD. Following Weedon et al. (2011), globally constant parameters with the values for short grass were used for the vegetation height and the surface resistance. However, the major land cover type in these areas is tropical forest. As Amazonian rainforest usually has a significantly higher ET than grassland (e.g. Costa and Foley, 1997; von Randow et al., 2004), PET is probably underestimated by the model leading to too extensive wetlands. Additionally, too low outflow could cause the cumulation of surface water and indicate an inability of the DWES to account for the specific wetland types in these regions. While the LSP2 and SIND do not contain any information on wetland types, these wetlands are classified as floodplains and swamp/flooded forests in the GLWD as well as forested and non-forest swamps in the MATT. In both maps these types occur most often in the tropics and are related to seasonal flooding. Thus, the overestimated tropical wetlands indeed belong to a certain wetland group. This fact gives rise to the assumption that the DWES might not be able to account for seasonal inundation or other floodplain processes in a realistic way. However, in comparison to the GRDC data, the peak flows of the Amazon and Congo catchments are simulated very well but the overall river discharge is already exceeding the observed values. A further increase in outflow velocity would lead to earlier peaks and increasing river discharge and thus decrease the model skill. Alternatively, the excess surface water could be related to an underestimation of soil storage capacity. In the MPI-HM the soil storage capacity is prescribed by the plant root depth. However, the real soil depth to the bedrock could exceed the root depth by some extent and store a considerable amount of the surface water. For these reasons, we assume that the PET computation or the soil bucket parametrization are causing the wetland overestimation rather than the DWES.

Compared to the LSP2 and SIND, the MPI-HM underestimates the wetland extent in Southeastern Asia. Both observation datasets are based on satellite products, which indicate the existence of surface water. These wetlands are not reported by the GLWD and MATT. Indeed, extensive wetlands exist in this region but these are mostly artificially formed (Mudge and Adger, 1995), e.g. due to irrigation. They are not captured by the model because the MPI-HM does not account for human impacts. The extent overestimation in the Eastern USA and Western Europe compared to the LSP2 and SIND can be attributed to the same shortcoming albeit in the opposite way. In these regions, existing wetlands were artificially drained (Finlayson and Davidson, 1999). Some regions lost more than $50 \%$ of their wetland area, e.g. the southwestern part of the USA (Dahl and Allord, 1996). However, these wetland losses were mainly caused by human impact rather than by climate change and are therefore not capture by the model. Instead, the DWES represents potential wetlands which could be sustained by climate conditions but were removed by landscape management.

Finally, the Siberian wetlands are underestimated compared to all observations. The underestimation is strongest for the GLWD and MATT and less pronounced for the LSP2 and SIND. This indicates that not all of the wetlands have surface water. Indeed, peatlands, which are most common in the high northern latitudes, are often waterlogged but not necessarily inundated. While water logged conditions are considered in the water balance calculations of the DWES, the wetland extent calculation requires surface water to compute any surface water changes (see Sect. 2.2). Conclusively, the DWES neglects most peatlands causing a general underestimation of wetland extent in the respective areas.

A major point of interest is the MPI-HM's skill to represent wetlands on grid cell scale. While seasonality of wetland extent and their water level variation are simulated with some confidence, the maximum wetland extent as well as the magnitude of lake level variations differ from observed values. In order to explore the reasons for these model deficits, the relation of the differences to a number of other model variables were investigated. Concerning the differences in maximum wetland extent, we find that they as well as their standard deviations are low for small simulated wetlands extent. Both increase for a larger wetland fraction and a larger overall water turnover. Obviously, the MPI-HM is better in identifying areas not suitable for wetland formation than in estimating the exact extent of wetlands that form in the remaining areas. Furthermore, the differences also depend on whether the wetland is dominated by vertical or horizontal water flows. Wetlands that are sustained mainly by horizontal flows are simulated too large by about $15 \%$ to $30 \%$ of grid cell area, whereas wetlands with predominantly vertical flows are simulated too little by about $0 \%$ to $5 \%$ grid cell area. Also, the standard deviation of about 0.3 in the first case is reduced to 0.1 in the second case. Decomposing the water flows into inflows and outflows, both flow components show a similar behaviour, although for the inflows, the decline in difference and standard deviation occurs not before the overall water flow comprises about $80 \%$ vertical flows. Finally, the differences are compared to the size of the upstream area for every wetland grid cell but no systematic bias is evident in this relation.

Concerning the lake level variations, the MPI-HM captures the seasonality of lake levels for about $50 \%$ of the 
investigated lakes but it underestimates their magnitude in almost every case. This deficiency is less for larger simulated wetland fractions and we assume this effect might be related to the sub-grid distribution of water bodies. In our sub-grid slope approach, we neglect the information about the exact positioning of wetlands within the grid cell and, thus, we cannot know whether all surface water is concentrated in a single wetland or distributed into several water bodies. Instead, the variation of water level is computed as average for all surface water bodies in the whole grid cell. In contrast, the satellite observations consist of average lake level variations over less than $0.3 \mathrm{~km}^{2}$ (GRLM, 2011), which is much smaller than the average $0.5^{\circ}$ grid cells. Thus, they probe only a single lake whose water level variations are not necessarily connected to the average variations in the grid cell area, which may lead to very different results. This deviation becomes smaller with larger lakes because then simulation and observations refer to the same area.

For some lakes, the MPI-HM computed no surface water at all. Beside a large water turnover which is needed for a robust water level computation, the model only works successfully for lakes which are in equilibrium with actual climate conditions. Among the 12 lake locations where the MPI-HM does not represent any surface water, some lakes could not be identified because they are not supported by the climate conditions during the simulation period. Examples for these are Lake Aral and Lake Chad. As these lakes rely on their water storage from the past, a model cannot simulate their extent using today's climate as forcing without realistic surface water initialization. Other lakes are artificial reservoirs and were not considered during the development of the DWES.

\section{Conclusions}

The scope of this study was the development and evaluation of the dynamical wetland extent scheme (DWES), which accounts for dynamical processes in wetland hydrology. Based on the newly developed flux equilibrium and sub-grid slope approaches, the DWES is able to transfer changes in the wetland water balance into variations of its surface extent. Therefore, not only the water table but the whole wetland might now react dynamically to changes in the Earth's climate.

During our analysis, we found that this simple approach is able to represent the spatial distribution of wetlands at a large scale as well as their seasonal variations well within the range of observations. In accordance with different global wetland and inundation observations, the model successfully identified the large wetland clusters in North America, Northern Europe as well as Western and Eastern Siberia. Furthermore, plausible seasonal variations in wetland extent are simulated that are related to northern snow melt and the cycle of rainy and dry seasons in the tropics.

However, the maximum extent of wetlands is computed with less confidence and is strongly overestimated in the tropics. This model deficit is mainly related to the dominant water flows in the wetlands and is strongest when the wetlands depend on horizontal flows. However, the integral overall horizontal water flows, which is the river discharge, already agrees with or even exceeds the observed values in such regions. Thus, we do not assume the horizontal flow formulation in our approach to be the cause of the overestimation as it cannot transport more water out of the basins without significantly decreasing the model skill in terms of river discharge. Instead, we assume a too low PET or a too small soil bucket to cause the cumulation of surface water. Further limitations of the model are its restriction of wetland extent dynamics to inundated areas and the neglect of human impacts. Both cause differences between simulated and observed wetland extent as neither peatlands, which often are waterlogged rather than inundated, nor artificially constructed or drained wetlands are considered in the model.

The DWES has some impact on the simulation of the water cycle on the regional scale. Most prominent are the increase of ET during summer time and the corresponding decrease of river discharge into the ocean. Also, well known effects of wetlands on river discharge like the delay and mitigation of peak flows are represented by the model.

Further development of the DWES will focus on an improvement of the wetland dynamics formulation in the DWES. It will be changed such that it can be applied not only to represent surface water dynamics but also to account for the spatial variation in soil moisture. Thus, non-inundated wetlands like peatlands may be represented, too. In the next step, the DWES will be implemented into a coupled ESM to explore whether its simulated impact of wetlands on the hydrological cycle causes significant feedbacks in the Earth system.

Acknowledgements. This research was undertaken as part of the European Union (FP6) funded Integrated Project called WATCH (contract number 036946). We thank Catherine Prigent for kindly providing the monthly inundation dataset to us and for her valuable comments about this paper. Furthermore, we thank four anonymous referees for their comments, which significantly improved our manuscript.

The service charges for this open access publication have been covered by the Max Planck Society.

Edited by: Y. Fan

\section{References}

Allen, R., Pereira, L., Raes, D., and Smith, M.: Crop evapotranspiration: Guidelines for computing crop water requirements, FAO Irr. Drain. Paper, 56, Rome, Italy, 1998.

Barling, R., Moore, I., and Grayson, R.: A quasi-dynamic wetness index for characterizing the spatial distribution of zones of sur- 
face saturation and soil water content, Water Resour. Res., 30, 1029-1044, doi:10.1029/93WR03346, 1994.

Beven, K. and Kirkby, M.: A physically based, variable contributing area model of basin hydrology, Hydrol. Sci. Bull. Sci. Hydrol., 24, 43-69, 1979.

Bohn, T., Lettenmaier, D., Sathulur, K., Bowling, L., Podest, E., and McDonald, K.: Methane emissions from western Siberian wetlands: heterogeneity and sensitivity to climate change, Environ. Res. Lett., 2, 045015, doi:10.1088/1748-9326/2/4/045015, 2007.

Bonan, G.: Sensitivity of a GCM simulation to inclusion of inland water surfaces, J. Climate, 8, 2691-2704, 1995.

Bowling, L. and Lettenmaier, D. P.: Modeling the Effects of Lakes and Wetlands on the Water Balance of Arctic Environments, J. Hydrometeorol., 11, 276-295, doi:10.1175/2009JHM1084.1, 2010.

Bullock, A. and Acreman, M.: The role of wetlands in the hydrological cycle, Hydrol. Earth Syst. Sci., 7, 358-389, doi:10.5194/hess-7-358-2003, 2003.

Coe, M.: Simulating continental surface waters: An application to holocene Northern Africa, J. Climate, 10, 1680-1689, 1997.

Coe, M.: A linked global model of terrestrial hydrologic processes: simulation of modern rivers, lakes, and wetlands, J. Geophys. Res-Atmos., 103, 8885-8899, doi:10.1029/98JD00347, 1998.

Coe, M.: Modeling terrestrial hydrological systems at the continental scale: Testing the accuracy of an atmospheric GCM, J. Clim., 13, 686-704, doi:10.1175/15200442(2000)013<0686:MTHSAT>2.0.CO;2, 2000.

Coe, M. and Bonan, G.: Feedbacks between climate and surface water in northern Africa during the middle Holocene, J. Geophys. Res-Atmos., 102, 11087-11101, doi:10.1029/97JD00343, 1997.

Costa, M. and Foley, J.: Water balance of the Amazon Basin: Dependence on vegetation cover and canopy conductance, J. Geophys. Res-Atmos., 102, 23973-23989, 1997.

Dadson, S., Ashpole, I., Harris, P., Davies, H., Clark, D., Blyth, E., and Taylor, C.: Wetland inundation dynamics in a model of land surface climate: Evaluation in the Niger inland delta region, J. Geophys. Res-Atmos., 115, D23114, doi:10.1029/2010JD014474, 2010.

Dahl, T. E. and Allord, G. J.: Technical aspects of wetlands. History of wetlands in the conterminous United States, National water summary on wetland resources, US Geological Survey WaterSupply Paper 2425, 1996.

Decharme, B., Douville, H., Prigent, C., Papa, F., and Aires, F.: A new river flooding scheme for global climate applications : Offline evaluation over South America, J. Geophys. Res-Atmos., 113, D11110, doi:10.1029/2007JD009376, 2008.

Decharme, B., Alkama, R., Papa, F., Faroux, S., Douville, H., and Prigent, C.: Global off-line evaluation of the ISBA-TRIP flood model, Clim. Dynam., 38, 1-24, doi:10.1007/s00382-011-10549, 2011.

Di Baldassarre, G. and Montanari, A.: Uncertainty in river discharge observations: a quantitative analysis, Hydrol. Earth Syst. Sci., 13, 913-921, doi:10.5194/hess-13-913-2009, 2009.

Finkelstein, S. and Cowling, S.: Wetlands, temperature, and atmospheric $\mathrm{CO} 2$ and $\mathrm{CH} 4$ coupling over the past two millennia, Global Biogeochem. Cy., 25, GB1002, doi:10.1029/2010GB003887, 2011.

Finlayson, C. M. and Davidson, N. C.: Global review of wetland resources and priorities for inventory: Summary report, in: Global
Review of Wetland Resources and Priorities for Inventory, edited by: Finlayson, C. M. and Spiers, A. G., Vol. 177 of Supervising Scientist Report, 1-14, Canberra, 1999.

Frey, K. and Smith, L.: How well do we know northern land cover? Comparison of four global vegetation and wetland products with a new ground-truth database for West Siberia, Global Biogeochem. Cy., 21, GB1016, doi:10.1029/2006GB002706, 2007.

Friborg, T., Soegaard, H., Christensen, T., Lloyd, C., and Panikov, N.: Siberian wetlands: Where a sink is a source, Geophys. Res. Lett., 30, CLM 5-1-CLM 5-4, doi:10.1029/2003GL017797, 2003.

Gedney, N., Cox, P., and Huntingford, C.: Climate feedback from wetland methane emissions, Geophys. Res. Lett., 31, L20503, doi:10.1029/2004GL020919, 2004.

Gesch, D., Verdin, K., and Greenlee, S.: New land surface digital elevation model covers the earth, Eos Trans. AGU, 80, 69-70, doi:10.1029/99EO00050, 1999.

Gioia, G. and Bombardelli, F. A.: Scaling and Similarity in Rough Channel Flows, Phys. Rev. Lett., 88, 14501-1-14501-4, doi:10.1103/PhysRevLett.88.014501, 2001.

Global Runoff Data Centre: Long-Term Mean Monthly Discharges and Annual Characteristics of GRDC Station, Tech. rep., Global Runoff Data Centre, Federal Institute of Hydrology (BfG), Koblenz, Germany, available at: $\quad$ http://www.bafg.de/cln_007/nn_298422/GRDC/EN/ 02__Services/02__DataProducts/LongTermMonthlyMeans/ longtermmonthly__node.html?__nnn=true, 2011.

Gorham, E.: Northern peatlands: role in the carbon cycle and probable responses to climatic warming, Ecol. Appl., 1, 182-195, doi:10.2307/1941811, 1991.

GRLM: USDA/FAS/OGA and NASA Global Agriculture Monitoring (GLAM) Project. Lake and reservoir surface height variations from the USDA's Global Reservoir and Lake (GRLM) web site. Altimetric lake level time-series variations from the Topex/Poseidon, Jason-1, Jason-2/OSTM, and Geosat FollowOn (GFO) missions., available at: http://www.pecad.fas.usda. gov/cropexplorer/global_reservoir/, 2011.

Hagemann, S.: An improved land surface parameter dataset for global and regional climate models, MPI-Report 336, Max Planck Institute for Meteorology, Hamburg, Germany, 2002.

Hagemann, S. and Dümenil, L.: A parametrization of the lateral waterflow for the global scale, Clim. Dynam., 14, 17-31, doi:10.1007/s003820050205, 1998.

Hagemann, S. and Dümenil, L.: Application of a global discharge model to atmospheric model simulations in the BALTEX region, Nord. Hydrol., 30, 209-230, 1999.

Hagemann, S. and Dümenil Gates, L.: Validation of the hydrological cycle ECMWF and NCEP reanalyses using the MPI hydrological discharge model, J. Geophys. Res. D Atmos., 106, 15031510, doi:10.1029/2000JD900568, 2001.

Hagemann, S. and Dümenil Gates, L.: Improving a subgrid runoff parameterization scheme for climate models by the use of high resolution data derived from satellite observations, Clim. Dynam., 21, 349-359, doi:10.1007/s00382-003-0349-x, 2003.

Hagemann, S., Botzet, M., Dümenil, L., and Machenhauer, B.: Derivation of global GCM boundary conditions from $1 \mathrm{~km}$ land use satellite data, MPI-Report 289, Max Planck Institute for Meteorology, Hamburg, Germany, 1999. 
Kaplan, J.: Wetlands at the Last Glacial Maximum: Distribution and methane emissions, Geophys. Res. Lett., 29, 1079, doi:10.1029/2001GL013366, 2002.

Kleinen, T., Brovkin, V., and Getzieh, R.: A dynamic model of wetland extent and peat accumulation: results for the Holocene, Biogeosciences, 9, 235-248, doi:10.5194/bg-9-235-2012, 2012.

Krinner, G.: Impact of lakes and wetlands on boreal climate, J. Geophys. Res. D Atmos., 108, 4520, doi:10.1029/2002JD002597, 2003.

Krinner, G., Lézine, A.-M., Braconnot, P., Sepulchre, P., Ramstein, G., Grenier, C., and Gouttevin, I.: A reassessment of lake and wetland feedbacks on the North African Holocene climate, Geophys. Res. Lett., 39, L07701, doi:10.1029/2012GL050992, 2012.

Lehner, B. and Döll, P.: Development and validation of a global database of lakes, reservoirs and wetlands, J. Hydrol., 296, 1-22, doi:10.1016/j.jhydrol.2004.03.028, 2004.

Levin, D., Hopper, I., Ernst, F., Trivett, M., and Worthy, N.: Evidence for a link between climate and northern wetland methane emissions, J. Geophys. Res. D Atmos., 105, 4031-4038, doi:10.1029/1999JD901100, 2000.

Matthews, E. and Fung, I.: Methane emission from natural wetlands: Global distribution, area, and environmental characteristics of sources, Global Biogeochem. Cy., 1, 61-86, doi:10.1029/GB001i001p00061, 1987.

Mishra, V., Cherkauer, K., and Bowling, L.: Parameterization of lakes and wetlands for energy and water balance studies in the great lakes region, J. Hydrometeorol., 11, 1057-1082, doi:10.1175/2010JHM1207.1, 2010.

Mudge, F. and Adger, W.: Methane fluxes from artificial wetlands: A global appraisal, Enviro. Manage., 19, 39-55, doi:10.1007/BF02472002, 1995.

O'Connor, F., Boucher, O., Gedney, N., Jones, C., Folberth, G., Coppell, R., Friedlingstein, P., Collins, W., Chappellaz, J., Ridley, J., and Johnson, C.: Possible role of wetlands, permafrost, and methane hydrates in the methane cycle under future climate change: A review, Rev. Geophys., 48, RG4005, doi:10.1029/2010RG000326, 2010.

Papa, F., Prigent, C., Aires, F., Jimenez, C., Rossow, W., and Matthews, E.: Interannual variability of surface water extent at the global scale, 1993-2004, J. Geophys. Res-Atmos., 115, D12111, doi:10.1029/2009JD012674, 2010.

Prigent, C., Matthews, E., Aires, F., and Rossow, W.: Remote sensing of global wetland dynamics with multiple satellite data sets, Geophys. Res. Lett., 28, 4631-4634, doi:10.1029/2001GL013263, 2001.

Prigent, C., Papa, F., Aires, F., Rossow, W., and Matthews, E.: Global inundation dynamics inferred from multiple satellite observations, 1993-2000, J. Geophys. Res-Atmos., 112, D12107, doi:10.1029/2006JD007847, 2007.
Rango, A. and Martinec, J.: Revisiting the degree-day method for snowmelt computations, Water Resour. Bull., 31, 657-669, doi:10.1111/j.1752-1688.1995.tb03392.x, 1995.

Ringeval, B., De Noblet-Ducoudré, N., Ciais, P., Bousquet, P., Prigent, C., Papa, F., and Rossow, W.: An attempt to quantify the impact of changes in wetland extent on methane emissions on the seasonal and interannual time scales, Global Biogeochem. Cy., 24, GB2003, doi:10.1029/2008GB003354, 2010.

Ringeval, B., Friedlingstein, P., Koven, C., Ciais, P., de NobletDucoudré, N., Decharme, B., and Cadule, P.: Climate- $\mathrm{CH}_{4}$ feedback from wetlands and its interaction with the climate$\mathrm{CO}_{2}$ feedback, Biogeosciences, 8, 2137-2157, doi:10.5194/bg8-2137-2011, 2011.

Singh, V.: Hydrological Systems: Rainfall-Runoff Modeling, Vol. 1, Prentice Hall, Englewood Cliffs, New Jersey, 1988.

St-Hilaire, F., Wu, J., Roulet, N., Frolking, S., Lafleur, P., Humphreys, E., and Arora, V.: McGill wetland model: Evaluation of a peatland carbon simulator developed for global assessments, Biogeosciences, 7, 3517-3530, doi:10.5194/bg-7-35172010, 2010.

Taylor, C. M.: Feedbacks on convection from an African wetland, Geophys. Res. Lett., 37, L05 406, doi:10.1029/2009GL041652, 2010.

Thornthwaite, C. W. and Mather, J. R.: The water balance, Pubbl. Climatol., 8, 1-104, 1955.

US Geological Survey: Global Land Cover Characteristics Data Base Version 2.0, online, available at: http://edc2.usgs.gov/glcc/ globdoc2_0.php (last access: 13 May 2010), 2001.

von Randow, C., Manzi, A., Kruijt, B., de Oliveira, P., Zanchi, F., Silva, R., Hodnett, M., Gash, J., Elbers, J., Waterloo, M., Cardoso, F., and Kabat, P.: Comparative measurements and seasonal variations in energy and carbon exchange over forest and pasture in South West Amazonia, Theor. Appl. Climatol., 78, 5-26, doi:10.1007/s00704-004-0041-z, 2004.

Weedon, G. P., Gomes, S., Viterbo, P., Shuttleworth, W. J., Blyth, E., Österle, H., Adam, J. C., Bellouin, N., Boucher, O., and Best, M.: Creation of the WATCH Forcing Data and its use to assess global and regional reference crop evaporation over land during the twentieth century, J. Hydrometeorol., 12, 823-848, doi:10.1175/2011JHM1369.1, 2011.

Yu, Z., Pollard, D., and Cheng, L.: On continental-scale hydrologic simulations with a coupled hydrologic model, J. Hydrol., 331, 110-124, doi:10.1016/j.jhydrol.2006.05.021, 2006. 